\title{
La Palestine : de la terre perdue à la reconquête du territoire
}

Jean-François Legrain

\section{(2) OpenEdition \\ 12 Journals}

Édition électronique

URL : http://journals.openedition.org/conflits/261

DOI : $10.4000 /$ conflits.261

ISSN : $1777-5345$

Éditeur :

CCLS - Centre d'études sur les conflits lilberté et sécurité, L'Harmattan

Édition imprimée

Date de publication : 15 mai 1996

ISSN : 1157-996X

Référence électronique

Jean-François Legrain, "La Palestine : de la terre perdue à la reconquête du territoire », Cultures \&

Conflits [En ligne], 21-22 | printemps-été 1996, mis en ligne le 15 mars 2006, consulté le 30 mars 2021.

URL : http://journals.openedition.org/conflits/261 ; DOI : https://doi.org/10.4000/conflits.261

Ce document a été généré automatiquement le 30 mars 2021.

Creative Commons License 


\title{
La Palestine : de la terre perdue à la reconquête du territoire
}

\author{
Jean-François Legrain
}

Aujourd'hui, alors que certains, tout particulièrement aux États-Unis et en Israël, voudraient substituer une logique de circulation marchande qualifiée de « moderne » à une logique territoriale disqualifiée comme "traditionnelle", au moment même où l'appropriation israélienne des terres palestiniennes n'a jamais été aussi forte, il paraît nécessaire de rappeler que la base du conflit israélo-arabe et israélo-palestinien est d'ordre territorial. Une même terre, la Palestine dans ses frontières du mandat britannique, se trouve disputée par deux nationalismes rivaux : un nationalisme juif (mais dans lequel tous les Juifs ne se reconnaissent pas : aussi ne faudrait-il pas parler de nationalisme judaïste, à l'image de l'idéologisation à des fins politiques de l'islam par l'islamisme ?) face à un nationalisme successivement arabe, palestinien et islamiste. Le nationalisme juif a vu le jour le premier dans le cadre du développement du mouvement sioniste qui a débouché sur la formation de l'État d'Israël, « aboutissement d'un processus qui s'insère parfaitement dans le grand mouvement d'expansion européo-américain des 19e et 20e siècles pour peupler ou dominer économiquement et politiquement les autres peuples ", selon l'expression de Maxime Rodinson ${ }^{1}$. L'identité nationale palestinienne, à laquelle se consacrera exclusivement cet essai, s'est construite plus tard en réaction au nationalisme israélien mais aussi à l'emprise paralysante du panarabisme. Dès la fin des années 1940, quand la communauté internationale a renoncé à considérer le nationalisme Juif comme le témoin d'un phénomène colonial, il est reçu qu'Israéliens et Palestiniens ont des droits égaux et inaliénables sur la terre de Palestine. Devant l'impossibilité de les faire vivre ensemble, cependant, le partage de la terre entre deux États est, dès cette époque, apparu comme la seule solution sensée et légitime. Cet essai visera à montrer comment, face à l'injonction de partage, la terre - ou plutôt la quête de sa récupération - a été de facto placée au coeur même de la construction nationale palestinienne à laquelle a présidé l'Organisation de Libération de la Palestine (OLP) depuis trois décennies maintenant. Confronté au quotidien de la privation de souveraineté sur cette terre, qu'il soit chassé en diaspora ou maintenu sous occupation, confronté aussi aux pressions 
internationales dans une logique affichée comme se résumant à «la terre contre la paix ", le peuple palestinien a, en effet, entamé et mené à son terme identitaire et politique un processus allant de la délimitation de sa terre en territoire à son appropriation symbolique pour en arriver à une renonciation raisonnée d'une partie du territoire construit au prix de la récupération de l'autre part. De façon délibérée, pourtant, et au mépris des principes affichés, les politiques israélienne et américaine, après avoir exigé de telles évolutions, se sont refusées à les prendre en considération, privant les Palestiniens de l'exercice de leur souveraineté sur une Palestine partagée. La Déclaration de principes sur des arrangements intérimaires d'autonomie signée à Washington le 13 septembre 1993 pouvait déjà se laisser lire en termes de simple manoeuvre visant à terme à légitimer internationalement le maintien des Palestiniens en situation de privation de souveraineté . Sa mise en oeuvre par les Israéliens, sous le regard bienveillant des Américains et d'une bonne part de la communauté internationale, comme le contenu des différents accords d'application signés tant au Caire le 4 mai 1994 (accord dit "Gaza-Jéricho d'abord») qu'à Washington le 28 septembre 1995 (accord dit « de Taba») ont levé tous les doutes qui pouvaient encore subsister: loin de préparer positivement à la seconde phase des négociations qui porterait, elle, sur le partage de souveraineté, l'accord intérimaire fonctionne comme une occasion offerte à Israël pour poursuivre en toute impunité ses décisions unilatérales en matière de judaïsation des terres, de confinement des Palestiniens dans des enclaves, et de dispersion du peuple palestinien, vidant ainsi dès aujourd'hui de son contenu toute négociation à venir. Bien au delà de l'échec personnel de Yasser Arafat et organisationnel de l'OLP, c'est le nationalisme palestinien lui-même, structuré sous l'égide de la centrale palestinienne, qui se trouve mis en échec et, en conséquence, délégitimé. Dès lors que l'espoir du recouvrement du territoire à court ou moyen terme apparaît de plus en plus chimérique et que la conscience se fait plus forte que l'occupation a fait de la cassure du lien social l'instrument de sa domination et de sa pérennisation, la construction identitaire qui avait fait du lien à la terre le fondement de l'identité de la personne, de l'unité de la nation et de l'agir de l'organisation, ne paraît plus opératoire. L'alternative islamiste aurait alors dû trouver sa capacité maximale d'attraction. En replaçant la Palestine au niveau eschatologique de la bénédiction divine et du combat entre le Bien et le Mal. En effet, le mouvement islamiste palestinien fait de la terre non plus la source de l'identité mais le lieu naturel de son épanouissement passé et futur. L'islam devient pour lui le fondement de l'identité de l'individu comme de la société. Immédiatement disponible, il permet la reconstruction, dès aujourd'hui, de l'unité du groupe qui n'est plus conditionnée par le retour au territoire. L'idée de reconquête n'est pas évacuée mais appelée à revenir, plus tard, dans l'unité reconstruite de la nation ; d'ici là, les capacités de négociations sur le quotidien de la part des organisations comme de la société seront d'autant plus fortes que le pérenne sera sauvegardé et renforcé. Plus de deux ans après la signature de la Déclaration de principes et en dépit de cette situation d'échec du nationalisme palestinien tandis que l'islamisme fait figure d'alternative de plus en plus crédible, l'OLP est parvenue à conserver, vraisemblablement de manière durable même si affaiblie et délégitimée, le contrôle des instances «étatiques» de l'autonomie. Avec l'appui d'Israël, elle a ainsi su exploiter à son propre profit l'extrême lassitude de la population palestinienne assoiffée de bien-être, loin de toute violence pour interdire à ses seuls compétiteurs potentiels l'accès au politique et le maintien de leur engagement militaire. Dans un tel contexte, les islamistes, dans leur courant majoritaire, 
apparaissent aujourd'hui prêts à renoncer à leur vocation à légitimement assumer l'héritage de l'OLP et du nationalisme dans les domaines tant militaire que politique, dans la suspension de la lutte armée et la mise en place d'un modus vivendi exempt de toute violence avec l'Autorité palestinienne. Repliés sur le religieux et le social abandonnés en échange par l'Autorité palestinienne, domaines dans lesquels ils excellent traditionnellement, les islamistes ont conscience d'être assurés d'accroître leur emprise sur une société privée de libération nationale comme de démocratie réelle. En renonçant à s'engager derrière la défense de ses propres résolutions adoptées dans le cadre des Nations-Unies, la communauté internationale, au moment même où elle aura salué la chute de l'apartheid en Afrique du Sud, aura ainsi assuré Israël de son soutien à la mise en place au Proche-orient de véritables «bantoustans d'Allah». Le sionisme, de façon paradoxale, se trouvera alors confronté à une sorte d'alter ego, un islamisme palestinien qui, avec une exploitation idéologique du référent religieux, cherchera à pallier les déficiences ethniques et territoriales pour, plus tard, dynamiser une reconquête de territoire.

De la perte de la terre au partage raisonné du territoire

3 L'histoire de ce siècle en Palestine peut être lue comme un processus allant de la terre au territoire. La privation progressive de la terre des ancêtres, travaillée sans être véritablement identifiée géographiquement ni liée à l'identité de ses habitants alors vécue de façon plutôt communautaire, a fait de cette terre le coeur d'une identité nationale en construction. La perte de l'ensemble de la Palestine et l'impossibilité militaire de la reconquérir ont, ensuite, conduit à sa conceptualisation en termes de territoire national appelant à une reconstruction de souveraineté selon les contours d'une carte dessinée par les politiques. Il s'agira ici de tracer les étapes de l'appropriation symbolique, par les Palestiniens, d'un territoire dont le contrôle leur échappait, dans un processus de différenciation nationale au sein de l'ensemble arabe. Passage obligé vers une désappropriation partielle et consentie de la terre en vue d'obtenir la souveraineté sur un territoire partagé.

4 La libération de la terre par l'expulsion des intrus Durant la première moitié de ce siècle, l'attitude adoptée par les Palestiniens et les Arabes peut être caractérisée par une volonté plus ou moins ferme de préservation de la terre face à la montée de l'immigration juive. La défaite arabe et la création de l'État d'Israël se sont, ensuite, traduites par l'expulsion d'une part importante de Palestiniens de leur patrie historique et une présence en constant essor d'une population nouvelle cimentée par une conscience nationale propre élaborée par les «Pères sionistes» depuis la fin du dix-neuvième siècle. Pour les Palestiniens, s'ouvre alors une période d'incapacité et de refus à prendre en considération la présence durable en Palestine de «Juifs » (de fait devenus « Israéliens » mais non considérés comme tels), parallèlement à une incapacité et un refus de construire une identité nationale palestinienne revendiquant une souveraineté palestinienne sur une terre identifiée en territoire distingué par des frontières de l'hinterland arabe (et islamique). Peuple et terre sont alors vécus comme " arabes ». Dans une dépendance totale vis à vis des États de la Ligue arabe et en plein engouement panarabe, les Palestiniens continueront ainsi jusque dans les années 1960 à penser la solution à apporter à la question de Palestine en termes de retour à la situation qui prévalait au début du vingtième siècle avant l'arrivée des colons sionistes. Il s'agissait ainsi de renvoyer dans leurs pays d'origine ou celui de leurs pères les Juifs extérieurs au Yishuv, la communauté juive de Palestine ; en ce qui les concernait eux- 
mêmes, la solution n'était pas vraiment pensée, en tout cas pas en termes d'État indépendant, toute issue revenant à une action concertée des États arabes ${ }^{3}$. La Charte nationale palestinienne adoptée par le premier Conseil national palestinien (CNP) (Jérusalem, juin 1964) peut être considérée comme le document de référence de cette étape. Le texte obéit à une dialectique non exempte de contradictions entre une territorialisation de l'identité arabe et l'ignorance de toute individualisation de la terre comme du peuple par rapport à l'ensemble arabe. Si son article 2 stipule bien, en effet, que « la Palestine, avec ses frontières de l'époque du mandat britannique, constitue une unité régionale indivisible ", l'article 1 avait pris soin d'insérer, par principe, cette unité territoriale dans l'ensemble régional : «La Palestine est une terre arabe, unie par des liens nationaux (qawmiyya) étroits aux autres pays arabes. Ensemble, ils forment la Grande nation arabe ». L'article 3 obéit ensuite à la même logique : « Le Peuple arabe de Palestine a le droit légitime à sa patrie. Il est une partie inséparable de la Nation arabe ». La Charte ignore ainsi tout « peuple palestinien ». Elle ne connaît qu'un Peuple arabe de Palestine, doté néanmoins d'une "personnalité palestinienne", " caractéristique permanente et authentique qui ne disparaît pas. Elle se transmet de père en fils ». Un seul critère, d'ordre territorial, semble permettre la différenciation du «Palestinien »: «Les Palestiniens sont les citoyens arabes qui ont normalement vécu en Palestine jusqu'en 1947, qu'ils y soient demeurés ou qu'ils en aient été expulsés (art. 6). En situation de privation de la terre d'origine, cette qualité devient héréditaire, le même article 6 précisant que " tout enfant né de parents palestiniens après cette date [1947], soit en Palestine même, soit à l'extérieur, est un Palestinien ». Pour la Charte, "la Déclaration Balfour, le Mandat et tout ce qui en a résulté sont des impostures " (art. 18). De même, « le partage de la Palestine en 1947 et la création d'Israël sont des décisions illégales et artificielles [...], parce qu'elles ont été contraires à la volonté du peuple de Palestine et à son droit naturel à sa patrie. Elles ont été prises en violation des principes fondamentaux contenus dans la Charte des Nations-Unies parmi lesquels figure au premier plan le droit à l'autodétermination » (art.17). C'est donc au nom de ce droit bafoué à l'autodétermination que la charte réclame «la libération de la Palestine » qu'elle entend comme la destruction concomitante de l'État d'Israël et le retour des nouveaux venus juifs à leur pays d'origine. Ne pourront, en effet, vivre en Palestine que les Juifs palestiniens dont la définition est donnée par l'article $7:$ : Les Juifs d'origine palestinienne sont considérés comme des Palestiniens, pourvu qu'ils veuillent vivre pacifiquement et loyalement en Palestine». Le texte exclut de la catégorie palestinienne l'ensemble des Juifs qui n'étaient pas des «citoyens arabes » ayant «normalement vécu en Palestine jusqu'en 1947 ». Toute prétention nationale du judaïsme est, par ailleurs, rejetée : «Les revendications au sujet des liens historiques et spirituels entre les Juifs et la Palestine ne sont pas conformes avec les faits historiques ou avec les bases réelles d'un État. Ce n'est pas parce que le judaïsme est une religion divine qu'il engendre une nation ayant une existence indépendante. De plus, les Juifs ne forment pas un peuple doté d'une personnalité indépendante parce qu'ils sont citoyens des pays auxquels ils appartiennent » (art. 18). Déniant toute légitimité au nationalisme juif, la Charte ne se revendique pas pour autant d'un nationalisme palestinien même si, comme on l'a vu, il est question d'une "personnalité palestinienne ». Il est bien clair pour le CNP que "l'unité arabe et la libération de la Palestine sont deux objectifs complémentaires » (art. 12). En outre, sous la pression de la Jordanie qui exerçait à l'époque sa souveraineté sur la Cisjordanie annexée, l'article 24 précise que l'OLP «n'exerce aucune souveraineté régionale (iqlîmiyya) sur la rive occidentale du 
royaume hachémite de Jordanie, sur la Bande de Gaza [...] ». Le rôle de l'organisation n'est donc que gestionnaire, l'OLP ayant « la responsabilité de l'action du peuple de Palestine dans sa lutte de libération de la patrie pour toutes les questions concernant la libération, l'organisation, la politique et les finances et pour tout ce que nécessite la question palestinienne, sur les plans arabe et international » (art.25). Aucune mention n'est faite d'une responsabilité militaire de l'OLP, la lutte armée étant alors du seul ressort des États dits « de la confrontation ». Ainsi, si la terre figure bien, dès l'origine, au coeur du discours de l'OLP, ce n'est qu'en tant qu'espace de vie particulier à une fraction du "peuple arabe ». La Palestine a, certes, une géographie - son extension mandataire - mais ne fait pas l'objet d'une appropriation autonome ni ne figure comme base d'une identité nationale. La lutte est israélo-arabe et la solution n'est pensée qu'en termes de libération entendue comme destruction de l'état d'Israël et renvoi de la majorité des Juifs vers leur pays d'origine. Nulle part, on ne trouve revendiquée la création d'un État palestinien, impensable en période de panarabisme triomphant et, de toute façon, exclue par la Jordanie.

5 L'État démocratique sur toute la Palestine La guerre de 1967, en entraînant l'effondrement des rêves panarabes du nassérisme, va conduire à l'émergence des Palestiniens comme acteurs autonomes sur la scène arabe, évolution qui se traduira institutionnellement par la prise de contrôle de l'OLP par le Fath de Yasser Arafat et la transformation de celle-ci de simple organisation manipulée par les États arabes en cadre de construction et d'expression de l'unité nationale. Cette "palestinisation » de l'OLP comme organisation sera menée parallèlement à une "palestinisation » de son idéologie avec l'apparition de l'idée de souveraineté nationale revendiquée sur la terre identifiée comme palestinienne et plus seulement comme arabe. La nouvelle version de la Charte nationale adoptée par la 4e CNP (Le Caire, juillet 1968) marque bien cette évolution de l'OLP. Dès l'article 1, la Palestine (toujours « dans les frontières du mandat britannique" selon l'article 2) est définie comme «la patrie du peuple arabe palestinien». Si le même article ajoute que la Palestine "constitue une patrie inséparable de la grande patrie arabe et le peuple palestinien fait partie de la Nation arabe », l'article 3 précise que « seul le peuple palestinien a des droits légitimes sur sa patrie. Après l'avoir libérée, il exercera son droit à l'autodétermination ». De la version de 1964 à celle de 1968, on est donc passé de «Peuple arabe de Palestine » au «Peuple arabe palestinien", arabité et palestinité étant bien marquées comme à la fois autonomes et complémentaires. Selon l'article 12, par exemple, «le peuple arabe palestinien croit à l'unité arabe. Pour jouer son rôle dans la réalisation de cette unité, il doit, dans l'étape actuelle de son combat national, sauvegarder son identité palestinienne [...], oeuvrer pour avoir une plus grande conscience de cette identité [...] ». Identité et coopération doivent ainsi régir les relations entre les États arabes et l'OLP : l'article 15 stipule que « la libération de la Palestine est une obligation nationale pour les Arabes ». Cependant, si l'article 27 avance, en effet, que l'OLP «n'interviendra dans les affaires intérieures d'aucun État arabe ", l'article 28 précise en retour que «le Peuple arabe palestinien affirme que sa révolution nationale (wataniyya) est authentique et indépendante. Il rejette toute forme d'ingérence, de tutelle ou dépendance ». Dans le même ordre d'autonomisation, l'OLP devient « responsable de la lutte du peuple palestinien pour libérer et retourner dans sa patrie » (art. 26) et étend dorénavant sa responsabilité au domaine militaire. L'article 24 de la Charte de 1964 qui soulignait l'absence de souveraineté de l'OLP sur la Cisjordanie, alors annexée par le royaume hachémite, et la Bande de Gaza, placée sous administration militaire 
égyptienne, ne figure plus dans la nouvelle version. Si l'OLP ne revendique pas encore la souveraineté pour elle-même sur ces territoires, elle le fait pour le peuple, le chemin y menant passant exclusivement par la lutte armée, « seule voie pour la libération de la Palestine ». «Il s'agit d'une ligne stratégique et non pas d'une ligne tactique », précise le texte qui poursuit: «Le Peuple arabe palestinien affirme sa détermination totale à mener la lutte armée et à lancer la révolution populaire pour la libération et le retour dans la patrie. Il affirme également son droit à mener une vie normale en Palestine et à y exercer le droit à l'autodétermination ainsi que sa souveraineté » (art. 9). Cette souveraineté implique non seulement la fin de l'État d'Israël mais également le départ des Juifs non palestiniens, dont une nouvelle définition plus explicite mais aussi plus restrictive qu'en 1964 est donnée puisque seuls « les Juifs qui résidaient habituellement en Palestine jusqu'au commencement de l'invasion sioniste sont palestiniens » (art. 6), dont la date est habituellement fixée en 1917. Alors même que la Charte est adoptée, un débat s'ouvre à l'initiative du Fath sur un État démocratique au sein duquel coexisteraient Musulmans, Chrétiens et Juifs, première réponse jugée alors pragmatique vis à vis des revendications nationales juives. Le 1er janvier 1969, à l'occasion du quatrième anniversaire du déclenchement de la lutte armée par le Fath, le Conseil central du mouvement publie ainsi une déclaration dans laquelle il réaffirme qu'il « rejette catégoriquement » la résolution 242 « qui ignore les droits nationaux du peuple palestinien », mais précise que « l'objectif final de sa lutte est la restauration de l'État palestinien indépendant et démocratique dont tous les citoyens, quelle que soit leur religion, jouiront de droits égaux » (art. 5). Le texte avait pris soin de préciser dans son article 2 que "le Fath ne lutte pas contre les Juifs en tant que communauté ethnique et religieuse. Il lutte contre Israël considéré comme l'expression d'une colonisation fondée sur un système théocratique, raciste et expansionniste, et comme l'expression du sionisme et du colonialisme ». Le 5e CNP (Le Caire, février 1969), au cours duquel le Fath prend le contrôle de l'OLP tandis que Yasser Arafat devient le président du Comité exécutif (CEOLP), adopte une résolution politique proche de la déclaration de janvier émise par le Fath puisqu'il y est signifié que l'objectif du peuple palestinien est « d'édifier une société libre et démocratique en Palestine, pour tous les Palestiniens qu'ils soient musulmans, chrétiens ou juifs, et de libérer la Palestine et son peuple de la domination du sionisme ". La mention explicite d'un État apparaîtra quelques mois plus tard dans les textes officiels de l'OLP. Une telle position, encore très ambiguë, rompait tant avec la vision traditionnelle de l'expulsion des Juifs non palestiniens vers leur pays d'origine qu'avec le panarabisme qui empêchait d'envisager la création d'un État autonome doté de souveraineté propre sur la patrie. L'introduction de la notion d'État ne signifie, cependant, en aucun cas un changement dans la stratégie de l'OLP pour laquelle «la lutte armée est la seule forme d'affrontement avec l'ennemi sioniste »; et c'est au nom de cette exclusivité de la lutte armée que l'OLP refuse toute solution politique, la formule de l'État démocratique étant introduite pour faire pièce à la résolution 242 qui ne mentionne à aucun moment les droits nationaux palestiniens. L'État démocratique n'est donc pas un plan ou un projet négociable mais un objectif stratégique. La libération de toute la Palestine demeure la condition préalable et nécessaire à l'établissement de cet État et aucun accommodement n'est envisageable avec les structures et les dirigeants sionistes. Pendant toute cette période immédiatement postérieure à la guerre de 1967, l'OLP met en oeuvre la " palestinisation » de sa lutte tout en veillant à éviter de s'isoler du monde arabe, et tout particulièrement de la Jordanie. C'est dans ce contexte donc que, face à 
l'occupation, la majorité des Palestiniens des territoires occupés demandent le retour au statu quo ante et que se développe une critique de l'idée de création d'une entité palestinienne dans les territoires occupés. Dès le 11 juin 1967, en effet, un certain nombre de personnalités palestiniennes de Cisjordanie avaient contacté des officiers israéliens et leur avaient proposé de réunir en assemblée une cinquantaine de notables qui demanderaient à Israël de les reconnaître comme représentants du peuple palestinien et négocieraient avec lui l'établissement d'une entité palestinienne calquée sur les lignes du plan de partage de 1947. D'autres offres avaient été également faites, toutes refusées tant par le gouvernement israélien, qui ne voulait que la Jordanie pour interlocuteur, que par les Palestiniens eux-mêmes dans leur majorité ${ }^{4}$. Dans une Charte des Arabes de la Cisjordanie du 4 octobre 1967, un échantillon représentatif du leadership local revendiquait ainsi le maintien de l'unité des deux rives du Jourdain et rejetait «le projet pernicieux de former un État palestinien supposé être un tampon entre les Arabes et Israël, mais qui sera étroitement lié avec la présence étrangère sioniste ». Pour ces leaders, il s'agissait de lutter contre une occupation territoriale certes mais aussi contre une judaïsation d'où le recours au caractère arabe, et pas seulement palestinien, de la résistance. Le 8e CNP (Le Caire, février 1971), d'ailleurs, avait renouvelé sa condamnation de "la création d'un État palestinien sur une partie seulement de la Palestine ». Selon Abu Iyad (Salâh Khalaf), un des fondateurs du Fath et membre du CEOLP, accepter un tel État équivalait à accepter la défaite des vingt années précédentes et donc l'existence de l'État d'Israël ; cet État serait un pont entre Israël et le monde arabe, vecteur de conquête économique ; Israël, de toutes façons, ne céderait ni Jérusalem, ni Gaza ni d'autres parties des territoires occupés; cet État, enfin, approfondirait le conflit entre la Palestine et la Jordanie ${ }^{5}$. En introduisant dans son appareil conceptuel la notion d'État démocratique palestinien, l'OLP traduisait la montée de sa prise de conscience nationale face à l'ensemble arabe, la création d'un État impliquant une individuation. La libération de toute la Palestine demeurait un préalable, toute idée d'entité palestinienne établie sur les seuls territoires occupés en 1967 étant rejetée. L'introduction, cependant, de l'idée d'État, en dépit d'une portée conceptuelle évidente, n'a cependant pas eu à l'époque de portée pratique considérable, l'OLP n'ayant alors aucune incidence internationale. La situation changea en 1973 lorsque la participation de l'OLP aux négociations s'affirma comme une question centrale.

6 Le territoire provisoirement partagé Les combats de septembre 1970 en Jordanie, la guerre d'octobre 1973 et les bouleversements locaux et régionaux ont, en effet, conduit la communauté internationale à évoluer et à considérer que la satisfaction des revendications nationales palestiniennes constituait un préalable à tout règlement durable de la question proche-orientale. L'OLP, de son côté, perçut qu'en s'en tenant à la thèse de l'État démocratique, et donc de la destruction de l'État d'Israël, elle s'excluait des conférences auxquelles elle pouvait prétendre participer et, par là, concourait à reporter la renaissance étatique palestinienne à un lointain avenir. Accepter une solution transitoire, c'était tenter de trouver une solution acceptable pour tous les alliés de la Résistance, la seule réaliste à court terme. La paternité de cette pensée "par étapes » revient au président tunisien, Habib Bourguiba, qui, dès janvier 1964, proclamait que " hors la politique des étapes, il n'y a pas de moyens efficaces ", principe traduit en 1965 puis en 1973 par un appel au retour au plan de partage de 1947. Elle fait son apparition dans le discours palestinien à l'occasion du débat sur le «pouvoir national» ouvert, dans les territoires occupés, par le Front national et, à 
l'extérieur, par le Front Démocratique de Libération de la Palestine (FDLP). Dans une lettre adressée au CEOLP le 1er décembre 1973, le Front national, structure clandestine mise en place en Cisjordanie-Gaza au lendemain même de l'occupation et dominée par des proches du Parti communiste, définit clairement que l'OLP doit aller à Genève pour obtenir la création d'un État palestinien en Cisjordanie-Gaza, les objectifs stratégiques, néanmoins, n'étant pas encore abandonnés. A l'extérieur, dans un discours tenu à l'université arabe de Beyrouth le 6 décembre 1973, le secrétaire général du FDLP, Nayef Hawatmeh, préconise quant à lui d'entrer « dans la lutte sous toutes ses formes, et les armes à la main, pour affirmer la présence indépendante de notre peuple sur toute la partie de sa terre dont les forces israéliennes se retireraient, que ce soit par la force, la menace de la force ou par un règlement imposé par les forces agissantes dans la région ». Et Hawatmeh de continuer : « Nous ne permettrons le retour d'aucune terre palestinienne au roi Hussein, ni l'annexion par Israël; il faut édifier un pouvoir national palestinien indépendant ${ }^{6}$. Implicitement, Hawatmeh désigne la Cisjordanie et Gaza. Il ajoute qu'il n'est pas question de reconnaitre Israël et que l'objectif stratégique reste l'État démocratique. Avant que l'idée de l'édification d'un pouvoir national palestinien en Cisjordanie-Gaza ne puisse l'emporter, il fallait que les Palestiniens fassent monter à la conscience et affichent leur identité nationale face à la Jordanie. C'est chose faite avec le 10e CNP et le congrès populaire qui le précède (Le Caire, avril 1972). Pour la première fois, en effet, les résolutions mentionnent l'existence d'un peuple jordanien et d'un peuple palestinien, poussant à une nécessaire alliance du mouvement jordanien et de l'OLP pour renforcer la lutte des deux peuples. Le texte demande également l'unité des deux rives du Jourdain sur des bases nouvelles d'égalité. "Ainsi, non seulement le rôle de l'OLP comme seul représentant du peuple palestinien est confirmé, l'existence de deux peuples affirmée, mais l'unité des deux rives est maintenant conçue comme unité de deux entités distinctes, que seul l'intérêt commun amène à s'unir " 7 . Lors du 12e CNP (Le Caire, juin 1974), le courant souhaitant un règlement politique qui permette l'édification d'un pouvoir national en CisjordanieGaza l'emporte sur celui qui souhaite que l'on s'en tienne à la Charte, tout règlement politique ne pouvant, selon ce dernier, aboutir qu'à l'édification d'un pouvoir nonnational. Le CNP adopte ainsi un Programme politique transitoire en 10 points. Le texte maintient le refus de la résolution 242 «qui ignore les droits nationaux de notre peuple ». «L'OLP emploiera tous les moyens, et en premier lieu la lutte armée, pour libérer le territoire palestinien et établir l'Autorité indépendante, nationale et combattante pour notre peuple sur toute partie du territoire palestinien qui sera libéré ». Ainsi, l'OLP se fixe pour la première fois un but intermédiaire qui n'est pas la libération de toute la Palestine, "premier pas vers l'acceptation, ultérieure et progressive, de l'idée qu'un autre État-Israël - puisse également exister sur le sol palestinien " ${ }^{8}$. L'article 3 complète cette position: «L'OLP luttera contre tout projet d'entité palestinienne dont le prix serait la reconnaissance, la paix, des frontières sûres, la renonciation à nos droits nationaux et la privation des droits de notre peuple au retour et à l'autodétermination sur le sol de sa patrie ». L'article 4, enfin, annonce que «toute étape vers la libération est une étape vers la réalisation de l'objectif stratégique de l'OLP qui est d'établir l'État démocratique palestinien ", ultime mention de cette revendication ignorée à partir du $13 \mathrm{e} \mathrm{CNP}$. Cette évolution de la centrale palestinienne précède de peu d'importants succès diplomatiques qui vont lui permettre de s'affirmer comme l'expression organisationnelle reconnue de la revendication nationale palestinienne. Le 7ème sommet arabe (Rabat, octobre 1974) fait ainsi de l'OLP le « seul 
et légitime représentant du peuple palestinien ", les États arabes affirmant que le peuple palestinien a le droit d'établir « un pouvoir national indépendant sous la direction de l'OLP [...] sur tout territoire palestinien libéré ». Les États de la Ligue arabe reconnaissent ainsi le succès de la conquête d'autonomie du nationalisme palestinien face aux revendications de tutelle jordaniennes. La communauté internationale connait une semblable évolution: en novembre 1974, Yasser Arafat est invité à s'exprimer devant l'Assemblée générale de l'ONU qui adopte la résolution 3236 reconnaissant les «droits inaliénables du peuple palestinien, y compris le droit à l'autodétermination sans ingérence extérieure et le droit à l'indépendance et à la souveraineté nationale ». Peu après, l'OLP affiche sa disposition à participer à la conférence de Genève sur la base de cette résolution 3236. Le passage du « pouvoir national » à «l'État » se fait peu à peu et la première mention d'un État indépendant qui ne serait pas forcément édifié sur toute la Palestine apparaît lors de la réunion du Conseil Central de l'OLP (CCOLP) de décembre 1976 (Damas, 12-14 décembre 1976) : « Le Conseil a noté que la liquidation de la présence israélienne dans les territoires occupés et la reconnaissance des droits nationaux de notre peuple, principalement son droit au retour, à l'autodétermination et à l'instauration d'un État indépendant sur son sol national étaient des questions au sujet desquelles la communauté internationale était désormais unanime, si l'on exceptait l'ennemi sioniste et son allié les État-Unis d'Amérique ». Le 13e CNP (Le Caire, mars 1977) confirme ces résolutions du CCOLP. La "palestinisation » est évidente dès l'article 1 dans lequel « le CNP affirme que la question palestinienne est le fondement et la substance du conflit arabo-sioniste [...] ». Dans l'article 11, le CNP annonce « décider de poursuivre la lutte pour récupérer les droits nationaux du peuple palestinien, et avant tout son droit au retour, à l'autodétermination et à l'établissement d'un État national indépendant sur le sol de sa patrie ». Cisjordanie et Gaza ne sont nulle part signifiés comme lieu de cet État, le CNP précisant que la récupération des droits nationaux doit se faire «sans paix ni reconnaissance d'Israël » (art. 9). Contrairement aux résolutions du précédent CNP, cependant, il n'est plus fait mention de l'objectif stratégique de l'État démocratique pas plus qu'il n'est question de la libération de l'ensemble de la Palestine. Les résolutions sont, néanmoins, émises sur la base de la Charte nationale palestinienne et des résolutions des précédentes sessions du Conseil national. Pour l'OLP, dorénavant, la lutte armée n'est plus le seul chemin et l'article 3 proclame « que toutes les formes de combat -militaire, politique ou populaire - dans les territoires occupés constituent l'élément fondamental de son programme de lutte [...] ». Pour la première fois, le CNP « souligne l'importance des relations et de la coordination l'intérieur et à l'extérieur de la patrie occupée avec les forces démocratiques et progressistes juives qui luttent contre l'idéologie et la pratique sionistes ». Le CNP, enfin, dans la ligne des acquis du sommet de Rabat, "réaffirme le droit de l'OLP à participer, d'une manière indépendante et sur un pied d'égalité, à toutes les conférences, réunions et efforts internationaux ayant trait à la question palestinienne [...]; déclare que tout règlement ou accord préjudiciable aux droits du peuple palestinien, conclu en son absence, est nul et non avenu ».

7 Le partage définitif dans la reconnaissance mutuelle Une fois acquise la thèse de l'État indépendant sur une partie de la Palestine, le débat va se porter sur la reconnaissance d'Israël, menant ainsi à son achèvement le processus d'acceptation raisonnée du partage. Il faudra, pour en arriver là, plusieurs années encore, la carte de la reconnaissance ayant été conservée le plus longtemps possible, considérée alors comme un atout dont l'OLP ne pourrait se départir que dans le cadre d'un échange de la 
reconnaissance par Israël du droit palestinien à l'autodétermination et à la construction d'un État. Les résolutions adoptées par le 16e CNP (Alger, février 1983), en acceptant le plan arabe de Fès de 1982 qui stipulait, dans son article 7, que « le Conseil de sécurité garantit la paix entre tous les États de la région, y compris l'État palestinien indépendant ", sont tout à fait typiques des ambiguïtés palestiniennes de cette époque. L'étape décisive ne sera ainsi franchie que sous la poussée de l'intifada avec la proclamation de l'État palestinien le 15 novembre 1988 lors de la clôture du 19e CNP (Alger) et les déclarations qui ont suivi. L'identité nationale liée au territoire est marquée dès le préambule de la proclamation: «Terre des messages divins révélés à l'humanité, la Palestine est le pays natal du Peuple arabe Palestinien. C'est là qu'il a grandi, qu'il s'est développé et s'est épanoui. Son existence nationale et humaine s'y est affirmée dans une relation organique ininterrompue et inaltérée entre le peuple, la terre et son histoire. Continuellement enraciné dans son espace, le peuple arabe palestinien a forgé son identité nationale [...] ». Assuré de ce lien entre le peuple et sa terre, «le CNP, au nom de Dieu et du peuple arabe palestinien, proclame l'établissement de l'État de Palestine sur notre terre palestinienne, avec pour capitale Jérusalem », tout en ajoutant : « l'État de Palestine est un État arabe, indissociable de la nation arabe». Fort de son indépendance étatique et de sa souveraineté sur le territoire, pourtant encore symboliques, l'OLP, pour la première fois de façon explicite, reconnaît que la résolution de partage de 1947 "assure aujourd'hui encore les conditions de légitimité internationale qui garantissent également le droit du peuple arabe palestinien à la souveraineté et à l'indépendance ». Si l'OLP ne reconnaît pas encore explicitement Israël, le droit à l'existence de ce dernier est juridiquement reconnu tandis que « l'État de Palestine affirme également qu'il croit au règlement des conflits régionaux et internationaux par des moyens pacifiques, conformément à la Charte et aux résolutions des Nations-Unies. Il condamne la menace de l'usage de la force, de la violence et du terrorisme, de même qu'il rejette leur utilisation contre son intégrité territoriale ou celle d'autres États ». La rupture avec les positions passées se fait tout aussi explicite avec la Déclaration politique adoptée par le même CNP dans laquelle l'OLP demande que les Palestiniens soient pleinement associés à une conférence internationale "qui doit être convoquée sur la base des résolutions 242 et $338 \mathrm{du}$ Conseil de sécurité, et des droits nationaux inaliénables du peuple palestinien [...] et en accord avec les résolutions de l'ONU relatives à la question de Palestine ». Pour la première fois, le $\mathrm{CNP}$ ne fait plus référence à sa Charte. Le texte donne également pour la première fois quelques indications sur les limites territoriales de cet État de Palestine puisque l'article 2 réaffirme la nécessité d'assurer le retrait d'Israël de tous les territoires palestiniens et arabes occupés depuis 1967, y compris la partie arabe de Jérusalem ", l'article 4 définissant explicitement que l'État palestinien exercera son autorité nationale sur « les territoires palestiniens occupés, y compris la partie arabe de Jérusalem » qui seront placés au préalable sous supervision des Nations-Unies. Le texte précise que le «CNP réaffirme ses résolutions antérieures concernant les relations privilégiées entre les peuples palestinien et jordanien. Il réaffirme également que les relations futures entre les États jordanien et palestinien seront de nature confédérale [...] ». Ces résolutions ne satisfaisant pas encore les États-Unis, Yasser Arafat les précise dans une conférence de presse tenue le 14 décembre 1988, au cours de laquelle il reconnaît nommément à Israël le droit à exister, réitérant la reconnaissance de la résolution 242 et le renoncement au terrorisme. En un quart de siècle, l'OLP est ainsi parvenue à conduire l'identification de la terre de Palestine en territoires partagés, 
palestinien et israélien, comme la construction d'une identité nationale palestinienne différenciée de l'ensemble arabe. Au terme de ce processus qui les avait amenés à entrer dans la logique de « la terre contre la paix», les Palestiniens ont légitimement attendu que leur droit à l'autodétermination et à la création de leur État, dans la logique du partage de 1947, leur fût enfin reconnu et entrât dans les faits. Telle, en tout cas, a été la demande expresse faite dès novembre 1988 avec la proclamation de l'État de Palestine.

Oslo ou la désillusion territoriale Cinq ans plus tard, force est de constater que l'ouverture du dialogue direct entre l'OLP et Israël et la signature le 13 septembre 1993 de la Déclaration de principes sur des arrangements intérimaires d'autonomie négociée dans le secret d'Oslo n'augurent en rien de l'établissement de ce partage de souveraineté entre l'État d'Israël et l'État de Palestine comme l'attendaient les Palestiniens au prix de leurs évolutions. A l'inverse, l'accord d'Oslo, dans sa mise en oeuvre comme dans ses textes, apparaît aujourd'hui comme l'expression la plus récente de la politique traditionnelle d'Israël visant à contourner la revendication palestinienne de souveraineté. Loin de préparer à un futur partage de territoires et de souverainetés, la Déclaration de principes et ses accords d'application du Caire et de Taba n'auraient alors servi qu'à réaménager l'occupation tout en consolidant la souveraineté de facto sinon de jure israélienne sur le territoire palestinien et ses ressources sans payer le prix politique de son annexion.

Le refus traditionnel, israélien et américain, de l'État palestinien Israël, depuis le milieu des années 1970, était parvenu à faire entrer les États-Unis dans sa politique de refus d'envisager des droits nationaux palestiniens et donc de l'éventualité de la création d'un État palestinien à ses côtés. La mise en oeuvre des résolution 242 et 338 du Conseil de sécurité, base imposée par la communauté internationale à tout règlement de la question proche-orientale, se trouve ainsi réduite, dans les visions israélienne et américaine, à un simple échange « de territoires » (conformément à la version anglaise de la résolution 242 mais en contradiction avec la version française qui, par l'article défini, exige un retrait de l'ensemble des territoires occupés en 67) entre États déjà existants. Dès le second accord de désengagement égypto-israélien (septembre 1975), et dans la perspective d'une reprise espérée de la conférence de Genève, Israël avait ainsi obtenu des États-Unis dans un memorandum d'accord signé par le secrétaire d'État, Henry Kissinger, et le vice-Premier ministre israélien, Ygal Allon, le refus de toute négociation et reconnaissance de l'OLP tant que celle-ci « ne reconnaitra pas le droit d'Israël à l'existence et n'acceptera pas les résolutions 242 et 338 ». Les États-Unis s'étaient alors également engagés « à faire opposition, et, si nécessaire, [à] voter contre toute initiative du Conseil de sécurité visant à modifier défavorablement les attributions de la Conférence de Genève, ou à modifier les résolutions 242 et 338 d'une façon qui serait incompatible avec leur objectif originel ", entendons ici la mention de droits nationaux palestiniens conformes, par exemple, à la résolution de partage de 1947. "Consultations approfondies" et "positions concertées" entre les deux gouvernements ont également été décidées, les États-Unis convenant qu'ils "déploieront tous leurs efforts pour obtenir que les négociations sur le fonds soient menées, à la Conférence [de Genève], sur une base bilatérale». Cette politique américaine, si l'on excepte une brève parenthèse début 1977, quand le président Jimmy Carter fit état des "droits légitimes du peuple palestinien ", ne sera jamais démentie par la suite. Le volet palestinien des accords de Camp David ne sera, d'ailleurs, qu'une version à peine amendée d'un plan élaboré en décembre 1977 par le Premier ministre 
israélien Menahem Begin, n'accordant aux Palestiniens qu'une autorité autonome fort éloignée de l'exercice de la souveraineté. Dans une «lettre de clarification » annexée aux accords et destinée aux Israéliens, Jimmy Carter reconnaissait, en outre, qu'il avait pris bonne note que les expressions "Palestiniens » et "peuple palestinien » sont et seront interprétées par Israël comme "Arabes palestiniens». Les États-Unis s'opposeront ensuite à ce qu'une Conférence internationale soit convoquée sur la base de la résolution adoptée par l'Assemblée générale de l'ONU le 12 décembre 1983 $(38 / 58 \mathrm{C})$ et qui faisait état des droits nationaux palestiniens. Si un dialogue est bien ouvert entre les États-Unis et l'OLP le 14 décembre 1988, l'OLP ayant répondu positivement aux conditions émises en 1975 par Henry Kissinger, il se referme en juin 1990 sans avancée notable. Ce refus d'envisager les droits nationaux des Palestiniens, base du refus des États-Unis de voir convoquer une Conférence internationale multilatérale, se maintient au delà même de l'ambiguïtés de certains termes employés. Le 6 mars 1991, dans son annonce devant le Congrès américain de son initiative de paix au Proche-orient, le président George Bush affirme ainsi qu'une " paix juste et durable au Moyen-orient doit être basée sur les résolutions 242 et 338 [...] et sur le principe de l'échange des territoires contre la paix [...] élaboré de manière à assurer la reconnaissance et la sécurité d'Israël et le respect des droits politiques et légitimes des Palestiniens». Le 11 avril 1991, néanmoins, lors d'une tournée du secrétaire d'État James Baker, le premier ministre israélien Yitzhak Shamir rend publics 9 «points d'accord » (ou prétendus tels, les États-Unis n'ayant cependant pas apporté de démenti) entre les États-Unis et Israël. Le second stipule que «les deux pays admettent que l'objectif final du processus de paix ne saurait être la création d'un État palestinien ». «Israël refuse tout dialogue avec l'OLP, et les États-Unis ne reprendront pas le dialogue avec la centrale palestinienne ", précise également le texte. En septembre 1991, à nouveau, mais cette fois dans leur Lettre d'assurances adressée à Israël et portant sur les modalités de la Conférence de Madrid, les États-Unis s'engagent à ne pas oeuvrer en faveur de la création d'un État palestinien en même temps qu'ils affirment leur hostilité au maintien de l'occupation; ils admettent également qu'il existe des interprétations différentes de la résolution 242 .

Sa mise en oeuvre dans les accords de Washington et du Caire La Déclaration de principes, certes, porte exclusivement sur la période intérimaire et exclut par définition le débat sur les questions de souveraineté mais également des réfugiés ou encore de Jérusalem, domaines qui ne seraient abordés que dans le cadre des négociations sur le statut final appelées à s'ouvrir au printemps 1996. Lors de sa signature, les analystes, dans leur grande majorité favorables à l'accord, ont avancé que tout était ouvert et que la mise en oeuvre de cette Déclaration déboucherait « naturellement » sur la création d'un État palestinien même si son principe n'avait pu figurer dans le texte. Tout lecteur attentif s'apercevra pourtant que la politique israélienne et américaine visant à priver les Palestiniens de tout droit à l'autodétermination, au retour et à l'édification de leur État est parvenue à s'imposer dans la rédaction de la Déclaration de principes. Les Palestiniens y ont, en effet, été contraints d'abandonner la référence à « toutes les résolutions de l'ONU pertinentes sur la question palestinienne » dont la 181 du partage de 1947, comme la 194 du droit des réfugiés au retour ou à compensation, ou encore les nombreuses résolutions de l'Assemblée générale qui, comme la 3236, font état des «droits nationaux inaliénables $\mathrm{du}$ peuple palestinien». L'article 1 de la Déclaration consacré à «l'objectif des négociations" et à leurs bases en matière de légalité internationale, fait ainsi 
exclusivement référence aux résolutions 242 et 338 du Conseil de sécurité qui, précisément, ignorent ces droits nationaux. Cette concession palestinienne n'a été obtenue, semble-t-il, qu'au prix de l'échange de lettres entre le premier ministre d'Israël et le président de l'OLP, échange désigné à tort comme une "reconnaissance mutuelle ». Si dans sa lettre Yasser Arafat confirme bien, en effet, que « l'OLP reconnaît le droit de l'État d'Israël à vivre en paix et dans la sécurité » et que « les articles de la Charte palestinienne qui nient à Israël le droit à l'existence [...] sont désormais inopérants et sans validité ", Yitzhak Rabin, quant à lui, se contente dans sa réponse de signifier qu'à « la lumière des engagements de l'OLP [...], le gouvernement d'Israël a décidé de reconnaître l'OLP comme le représentant du peuple palestinien et d'ouvrir des négociations avec l'OLP dans le cadre du processus de paix au Proche-orient " 9 . Seules la renonciation au sionisme et la reconnaissance des droits nationaux palestiniens par Israël, parallèles à la renonciation des Palestiniens à la Palestine tout entière, auraient constitué une authentique "reconnaissance mutuelle». La mise en oeuvre de la Déclaration par Israël, comme le contenu de ses différents accords d'application, accords du Caire (Oslo I) et de Taba (Oslo II), semblent bien indiquer que le processus est effectivement destiné à exclure l'éventualité de la création d'un État palestinien doté des prérogatives habituelles de tout État. En cette période postérieure à la Guerre froide, l'accord de Washington peut ainsi être considéré comme la traduction objective du rapport de forces existant entre Israël et les Palestiniens, ou, plus généralement, entre la communauté internationale et le monde arabe. L'un des cosignataires, Israël, peut être considéré comme le vainqueur tandis que l'autre est le vaincu. A aucun moment le vainqueur n'a transcendé l'objectivité du rapport des forces au nom d'une vision politique à long terme. Après avoir choisi publiquement l'OLP comme partenaire, Israël, dans sa mise en oeuvre d'Oslo I, avait ainsi semblé être retourné à sa politique traditionnelle de refus, n'offrant, en tout cas, aux Palestiniens aucun signe de bonne volonté. Aucune des dates mentionnées par l'accord n'avait été respectée : le redéploiement de l'armée israélienne dans la Bande de Gaza et hors de la zone de Jéricho s'était effectué avec plus de 5 mois de retard; le redéploiement général en Cisjordanie et l'organisation d'élections pour le Conseil palestinien d'autonomie avaient dû être renégociés dans le cadre d'Oslo II et n'avaient pu être menés à bien qu'en décembre 1995-janvier 1996 alors même qu'ils devaient s'effectuer «au plus tard» le 13 juillet 1994. L'élimination physique des Palestiniens n'avait pas connu de répit: pour la seule période allant du 13 septembre 1993 au 30 novembre 1994, 164 Palestiniens avaient été tués par l'armée, bon nombre d'entre eux exécutés sur ordre dans le cadre des activités des unités camouflées ${ }^{10}$. Bien que le massacre d'Hébron de février 1994, au cours duquel un colon avait tué de sang-froid une trentaine de Palestiniens en prière dans le Harâm d'Abraham, ait été un acte individuel, il était alors devenu pour les victimes une sorte de casus belli officiel lancé par le gouvernement israélien lui-même: la répression des manifestations populaires de condamnation avait, en effet, conduit à multiplier par plus de deux le nombre de morts tandis que les Palestiniens s'étaient vus dépossédés d'une grande partie du Harâm au profit des Juifs. La libération attendue des milliers de prisonniers n'avait eu lieu que très partiellement tandis que les nouvelles arrestations se multipliaient. Loin d'apporter une amélioration dans le domaine économique, l'accord avait entraîné une chute du niveau de vie dans les zones autonomes, la fermeture du marché du travail israélien à la main-d'oeuvre palestinienne décidée après la multiplication d'opérations militaires anti-israéliennes accentuant l'asphyxie des territoires autonomes et occupés. En matière de judaïsation 
des territoires occupés ${ }^{11}$, Yitzhak Rabin n'a jamais cherché à arrêter le processus ni même à le ralentir; il a simplement travaillé à le réorienter pour répondre aux exigences économiques et démographiques liées au tarissement de l'immigration soviétique et se gagner l'aide américaine à moindre coût. Dès le début 1992, d'ailleurs, Yitzhak Shamir lui-même avait déjà entamé le processus de réduction des investissements en matière de logement face à cette situation inattendue d'arrêt de l'immigration qui fera qu'en 1993 le nombre d'appartements qui n'avaient pas trouvé preneur dans l'ensemble d'Israël et des territoires occupés était estimé à quelque 44.000 unités. La situation s'étant stabilisée, Yitzhak Rabin reprit la politique de Yitzhak Shamir puisqu'en 1994, le montant des investissements consentis à la colonisation dépassait de $70 \%$ ceux de l'année précédente ${ }^{12}$. Ces quelques gesticulations (par exemple l'intervention de l'armée en décembre 1993 pour empêcher le plan «doublement " lancé par les colons et visant à créer 130 nouvelles implantations) suffiront à une communauté internationale bienveillante. Elles lui feront également « oublier » tant la complaisance du premier ministre face à la radicalisation croissante de la population de ces colonies dont il sera la plus emblématique victime, que son refus de tout démantèlement jusque dans les suites de la tuerie du Harâm d'Hébron, à un moment pourtant où l'immense majorité de son opinion publique aurait approuvé le retrait du coeur de la ville des quelques dizaines de familles juives prêtes à lancer le pays dans une aventure sanglante. Si l'on considère le nombre d'unités de logement dont la construction a été soit lancée soit achevée, la décision de gel annoncée par Yitzhak Rabin en juillet 1992 ne s'est pas traduite dans les faits: durant les neuf premiers mois qui ont suivi cette décision (juillet 1992-mars 1993), Jérusalem étant exclu, 18,6\% des 8290 unités lancées l'ont été dans les territoires (sous Yitzhak Shamir, le chiffre n'était que de $10,8 \%$ des 61600 unités lancées) ${ }^{13}$. En matière d'investissement, le gouvernement Rabin a poursuivi la politique dynamisée par le Likud d'incitation à l'installation au delà de la «Ligne Verte » qui séparait Israël et Jordanie jusqu'en 1967 : en 1994, les colons qui ne représentaient que $2,4 \%$ de la population israélienne bénéficiaient de $12 \%$ du budget domestique et bénéficiaient ainsi d'un niveau de vie supérieur aux Israéliens installés en Israël même ${ }^{14}$. Du point de vue de la démographie, selon le Bureau central de statistiques Israélien, la population des colonies (JérusalemEst exclu) est passée de 105000 en 1992 à 115000 en 1993, soit un accroissement de 9,3\%, taux plus élevé que tous ceux relevés dans les différentes régions d'Israël même. Selon le YESHA ("Conseil des implantations en Judée-Samarie et Bande de Gaza »), l'accroissement n'aurait été que de 7,3\%, la population passant de 126400 à 136415 colons. Après un ralentissement observé en 1993-1994, la croissance démographique reprend en 1994-1995 puisque le nombre de colons serait passé dans la Bande de Gaza de 5000 en septembre 1993 à 8000 en mai 1995, et de 130000 en Cisjordanie à $160000^{15}$. A Jérusalem-Est, le gouvernement Rabin n'a fait que poursuivre la mise en oeuvre des plans annoncés en octobre 1990 par Ariel Sharon, alors ministre du gouvernement Likud, dont l'intention était d'accroître de $50 \%$ la population juive (alors 120000 ) par la construction de 15000 logements pour la période 1990-1993 ${ }^{16}$. Avec le tarissement de l'immigration soviétique, la moyenne annuelle de construction de nouveaux logements s'était établie autour de 3000 unités qui venaient ainsi s'ajouter aux 38500 déjà construites, la population juive de Jérusalem-Est atteignant le chiffre de 168000 personnes ${ }^{17}$. Dès le début 1995 , la course à la judaïsation reprenait et Benjamin Ben Eliezer, ministre du Logement et de la Construction, annonçait le 4 mai 1995 l'intention du gouvernement de construire dans les cinq années à venir 30000 nouveaux 
logements dans l'ensemble de la municipalité (Est et Ouest), projet qui nécessiterait de nouvelles expropriations. Grâce à cette politique, Israël a atteint son but à savoir l'établissement d'une majorité juive sur l'ensemble de la municipalité, y compris au sein du seul périmètre de Jérusalem-Est privé de tout habitat juif avant la guerre de 1967. La planification démographique du gouvernement israélien pour l'ensemble de Jérusalem serait ainsi guidée par la volonté de maintenir un rapport d'au moins 7 à 3 à la défaveur des Palestiniens. Pour parvenir à cette fin, se superposent à la politique de la construction massive : 1 - une politique de confiscation des cartes de résidents à tous les Palestiniens certes nés dans la ville mais qui l'auraient ensuite quittée pour s'installer en Cisjordanie (entre 50 et 80000 personnes pourraient entrer dans cette catégorie ${ }^{18}$ ) ; 2 - une politique d'étouffement économique par les mesures prises par Israël le 17 janvier 1991 et renforcées en mars 1993 interdisant l'accès à son territoire, et par là même à Jérusalem annexée, à tout Palestinien non résident dépourvu de permis $^{19}$. L'ensemble de ces politiques jointes à la répression multiforme ont ainsi favorisé une émigration importante puisque, selon un bilan établi en 1993, 16917 Palestiniens de Jérusalem auraient émigré vers l'étranger depuis 1967 tandis que 12080 autres auraient quitté les limites de Jérusalem annexée ; 7 630, absents lors de la guerre de 1967, n'ont, par ailleurs, jamais pu revenir chez eux ${ }^{20}$. Si la moyenne mensuelle de confiscation de terres s'élevait à 2500 dunums juste après la Conférence de Madrid de 1991, elle était passée à 8400 dunums après Oslo ${ }^{21}$. Ainsi, sur l'ensemble des territoires occupés, quelque 146044 dunums auraient été confisqués entre la signature de l'accord d'Oslo et le 1er janvier $1995^{22}$. En 1991, on estimait que $65 \%$ de la superficie de la Cisjordanie et $42 \%$ de la Bande de Gaza étaient passés sous contrôle israélien ${ }^{23}$; selon un rapport des Nations-Unies de $1995^{24}$, le contrôle israélien s'étendrait aujourd'hui à $73 \%$ de la Cisjordanie et de la Bande de Gaza. S'il faut en croire Shlomo Gazit, ancien chef du renseignement israélien ${ }^{25}$, « selon les chiffres disponibles, durant les quatre années de ce gouvernement travailliste, Israël achèvera la construction de 30000 logements dans les territoires, permettant ainsi d'accroître la population de 120000 personnes. Durant les 5 années de la période intérimaire, la population [juive] de Judée-Samarie aura ainsi doublé ». Au terme d'une réunion interministérielle tenue en janvier 1995, le gouvernement israélien a, en effet, décidé d'adjoindre aux 11000 logements hérités du Likud et achevés depuis juin 1992 en Cisjordanie et 13000 à Jérusalem-Est, la construction durant la période 1995-1998 de 15000 logements dans Jérusalem-est annexée, 13000 dans le "Grand Jérusalem» et 3000 ailleurs en Cisjordanie. Cette intensification de la colonisation, le refus d'ouvrir les routes de libre-passage entre les enclaves autonomes de Gaza et de Jéricho comme prévu dans la Déclaration, ou encore le déni de souveraineté fait aux Palestiniens en zones autonomes sur le sous-sol et les espaces aérien et maritime n'ont conduit qu'à rendre encore plus illusoires les espoirs de récupération future d'une souveraineté minimale. Signé au Caire le 4 mai 1994, l'accord dit « Gaza/Jéricho d'abord » ne fait, en effet, qu'entériner tout en la renforçant la mainmise israélienne sur les terres palestiniennes comme la protection déjà accordée aux colonies par la Déclaration de principes. Au terme de l'accord, en effet, les implantations, leurs habitants et leurs ressources en terre et en eau échappent à la juridiction palestinienne. En ce qui concerne la Bande de Gaza, Israël maintient son contrôle sur quelque $40 \%$ de sa superficie ${ }^{26}$ et la géographie de l'autonomie montre bien le caractère central de l'existence des colonies qui, dans la perspective de Yitzhak Rabin, loin de gêner l'exécution de l'accord, en sont la condition. Les implantations, en effet, sont au coeur du contrôle militaire de la zone et il n'a jamais été question, par 
exemple, pour le premier ministre de se priver de Netzarim, colonie de quelques dizaines d'habitants civils située juste entre la ville de Gaza et les camps de réfugiés de sa banlieue sud. Au nom de la nécessaire desserte de ces colonies, la bande de Gaza se retrouve ainsi sillonnée de routes militaires qui sont contrôlées soit par l'armée israélienne seule soit par des patrouilles mixtes israélo-palestiniennes. L'ensemble des points d'entrées en zones autonomes se situant sur ces routes militaires, Israël et son armée peuvent à tout moment couper la Bande de Gaza en plusieurs zones étanches entre elles. En Cisjordanie, l'accord maintient le Jourdain en tant que «frontière de sécurité » et prive ainsi la zone de Jéricho de tout accès au fleuve comme à la Jordanie. Là encore, toute la géographie de l'autonomie a été dessinée autour du concept de maintien des colonies et de leur exclusion de la zone palestinienne, Jéricho étant réduite à $62 \mathrm{~km}^{2}$ de dentelle alors que son district couvrait plus de $200 \mathrm{~km}^{2}$ à l'époque jordanienne. En excluant Jérusalem de son champ d'application, enfin, la Déclaration de principes donne une certaine légitimité aux faits accomplis israéliens tandis qu'une loi qualifiée de "mise en oeuvre des accords d'Oslo et du Caire " permet dorénavant aux autorités de fermer les institutions palestiniennes de la ville qui entretiendraient des liens institutionnels avec l'Autorité autonome exclusivement cantonnée aux zones qu'elle contrôle.

11 Son renforcement avec l'accord de Taba La tâche d'Oslo II vise, semble-t-il, à parvenir aux mêmes résultats en étendant le confinement des Palestiniens dans des enclaves à l'ensemble de la Cisjordanie. Selon l'accord négocié à Taba et signé le 28 septembre 1995 à Washington, trois zones ont ainsi été définies : Une zone A, soit moins de $4 \%$ de la superficie de la Cisjordanie et $20 \%$ de sa population, comprend les sept grandes cités palestiniennes (Jénine, Qalqilya, Tulkarm, Naplouse, Ramallah, Bethléem et Hébron), Jérusalem-Est annexée étant exclue par définition; à l'exception de 25 à $30 \%$ de la superficie municipale d'Hébron, cette zone A, devrait être évacuée d'ici le printemps 1996, et se retrouver sous le contrôle de l'Autorité palestinienne, chargée des pouvoirs civils et de police, l'armée israélienne pouvant cependant intervenir dans le cadre de patrouilles conjointes. Aucun engagement ne figure sur un retrait ultérieur d'Hébron de plus ample importance. Une zone B comprend la quasi totalité des 450 villages palestiniens, soit environ $23 \%$ de la Cisjordanie ; l'Autorité palestinienne n'y sera dotée que des pouvoirs civils et d'une partie des pouvoirs de police, l'armée israélienne y conservant la responsabilité de la sécurité et le droit d'intervention unilatérale à tout instant. Une zone C, enfin, soit quelque $73 \%$ de la superficie de la Cisjordanie, comprend les zones non peuplées, les zones dites "stratégiques" et les colonies; elle demeure sous le contrôle exclusif israélien. Un vague calendrier prévoit d'autres retraits israéliens ultérieurs au sein de cette zone $\mathrm{C}$ sans, cependant, aucun engagement sur leur ampleur. Ce démembrement de la Cisjordanie en une multitude de régions et zones, urbaines ou rurales, non contiguës, parfois un peu étendues, le plus souvent minuscules a conduit les observateurs à parler de «la peau de léopard » d'Oslo II ou encore "d'archipel micronésien " ${ }^{27}$. Le nouvel accord, en tout cas, réaffirme et, dans certains domaines même, étend les protections accordées aux colonies et à leurs habitants déjà garanties dans l'accord du Caire de mai 199428: l'accord stipule qu'aucune implantation ne saurait être évacuée durant la période intérimaire. Les colonies, les colons et les « artères vitales » (routes principales, adductions d'eau, lignes téléphoniques et électriques) de même que les ressources en eau échapperont à toute juridiction, interférence ou contrôle palestiniens. Des blocs de colonies seront créés afin d'assurer la continuité territoriale entre eux. Des arrangements extensifs et 
complexes de coopération en matière de sécurité seront passés entre les diverses forces israéliennes et palestiniennes militaires et de sécurité afin de limiter les contacts entre, d'une part, colonies et colons et, d'autre part, autorités palestiniennes dans les domaines policier, judiciaire et juridique. Les forces palestiniennes de sécurité seront limitées en nombre, en armement et en matière de juridiction. L'usage des terres jouxtant les colonies sera limité pour les Palestiniens et les décisions touchant au zonage et à l'utilisation de terres demeureront sous la supervision israélienne. L'accord de Taba réaffirme en outre ce que stipulait l'accord du Caire selon lequel la législation palestinienne ne pourra « concerner les questions de sécurité qui ne relèvent que de la responsabilité israélienne ». Il est également signifié que le futur Conseil palestinien devra « reconnaître les droits légaux des Israéliens relatifs aux terres domaniales et aux terres aux propriétaires absents localisés dans les zones placées sous juridiction territoriale du conseil », ce qui implique le maintien du contrôle israélien sur ces terres dans les zones A et B sans parler bien évidemment de la zone C. Selon des sources palestiniennes citées par le même rapport, les Palestiniens auraient ainsi reconnu à Israël le contrôle sur presque $90 \%$ de la superficie de la zone B. Alors que les colonies n'occupent qu'environ $16 \%$ de la superficie des terres domaniales qui constituent ellesmêmes quelque $70 \%$ de la Cisjordanie, les $54 \%$ restant, terres incultes pour la plupart, ne font même pas l'objet d'une promesse de restitution aux Palestiniens. La question de l'eau n'ayant pu être réglée, il convient également de mentionner qu'Israël continuera donc de disposer jusqu'aux négociations sur le statut final des nappes acquifères dont il accapare la majeure partie pour l'usage de sa population dans ses frontières de 1949 et ses colons ${ }^{29}$. La maîtrise de l'eau, une nouvelle fois, apparaît bien ainsi comme un objectif central pour les Israéliens. Selon Yaakov Tsur, ministre de l'Agriculture, Israël «tire aujourd'hui plus du tiers de sa consommation d'eau potable de trois grandes nappes phréatiques» partiellement ou totalement situées en Cisjordanie ${ }^{30}$. Au total, selon le ministre, ces trois nappes produisent 650 millions de $\mathrm{m} 3$ par an dont 130 millions seulement sont destinés aux Palestiniens. La plus grande, la nappe occidentale, se situe à l'ouest d'une ligne Hébron-Ramallah et s'étire jusqu'à la Méditerranée ; plus de 350 millions de $\mathrm{m} 3$ y sont pompés chaque année. La seconde nappe s'étend quant à elle entre Jénine et Naplouse et produit 140 millions de m3 par an. La nappe orientale, enfin, couvre le reste de la Cisjordanie ; capable de produire 170 millions de $\mathrm{m} 3$, elle est aujourd'hui sous-utilisée. C'est de cette nappe exclusivement que les Palestiniens seraient autorisés à augmenter leur part de pompage. D'ores et déjà de gigantesques investissements sont faits en matière de création de routes dites « de contournement " de même que les infrastructures des colonies sont renforcées : installation de sécurité, grillages, barbelés, routes, véhicules de patrouilles, renforcement de la présence militaire, nouvelles adductions d'eau et d'électricité séparées des réseaux palestiniens, etc. Avec l'aval de la communauté internationale au nom de la défense des accords d'Oslo, Israël est ainsi en train de renforcer l'interconnection de ses différents réseaux (routes, électricité, eau) des territoires occupés avec celui de la plaine côtière, de faciliter le transport des colons entre les colonies et dans une ultime étape d'exclure non plus seulement de facto mais aussi de jure les Palestiniens de ces nouveaux réseaux exclusivement réservé aux Israéliens. En ayant signé l'accord de Taba, le chef de l'Autorité palestinienne a ainsi donné légalité à cette politique qui, par là même, ne peut plus être disqualifiée comme unilatérale. Et d'ores et déjà, chacun peut imaginer ce que seront les propositions israéliennes en matière territoriale. Dans son discours de demande de ratification de l'accord de Taba par la Knesset le 5 octobre 1995, Yitzhak 
Rabin, en effet, s'est montré très clair: "Nous envisageons la solution permanente [entre nous, les Palestiniens et les États arabes] dans le cadre de l'État d'Israël qui inclura la majeure partie de la terre d'Israël telle qu'elle était sous le mandat britannique, aux côtés d'une entité palestinienne qui sera une patrie [home] pour la plupart des résidents palestiniens qui vivent dans la Bande de Gaza et en Cisjordanie. [...] Nous ne retournerons pas aux frontières du 4 juin 1967. Voici les principaux changements, et non l'ensemble d'entre eux, que nous préconisons et voulons voir figurer dans la solution permanente : A - Tout d'abord, Jérusalem unifiée, qui inclura à la fois Ma'ale Adumim et Givat Ze'ev, en tant que capitale d'Israël sera sous souveraineté israélienne, tout en préservant les droits des membres des autres cultes, christianisme et islam, de libre accès et libre pratique dans leurs lieux-saints [...]. B - La frontière de sécurité de l'État d'Israël sera située dans la vallée du Jourdain, au sens le plus large du terme. C - Les changements incluront également le Gush Etzion, Efrat, Beitar de même que d'autres implantations pour la plupart situées à l'est de ce que fut la Ligne Verte avant la Guerre des Six jours. D - Des blocs d'implantations seront établis en Judée et Samarie à l'image du Gush Katif [dans la Bande de Gaza]. [...] Nous nous sommes engagés à ne pas éradiquer une seule implantation dans le cadre de l'accord intérimaire et à n'empêcher d'aucune façon la construction liée à la croissance naturelle [...]» ${ }^{31}$. De telles propositions recoupent sur bien des points, celles préconisées par un groupe de pression, The Third Way (La troisième voie), opposé à la fois au maintien du contrôle israélien sur les Palestiniens et à la rétrocession pure et simple des territoires occupés en 1967; fondé en mai 1994 par une quinzaine de députés travaillistes menés par Yehuda Harel, leader des colons du Golan, le groupe draine autour de lui tant des faucons travaillistes que des colombes du Likud et se revendique de la tradition de l'ancien premier ministre Golda Meïr, de Yisraël Galili, son éminence grise, le père de la politique israélienne menée dans les territoires occupés de 1973 à 1977, et de Yigal Allon ${ }^{32}$. Même si le groupe critique l'accord de Taba, il ne fait guère de doute que c'est vers les solutions territoriales qu'il préconise que se dirige le gouvernement israélien actuel. Tout indique, ainsi, aujourd'hui que les récents accords ne constituent qu'un nouveau mode d'exercice de l'occupation et non sa fin : établir un contrôle sur les Palestiniens non plus de l'intérieur par la présence de l'armée israélienne dans les zones peuplées mais de l'extérieur par les Palestiniens euxmêmes, victoire tant attendue d'Israël après l'échec d'une telle délégation offerte à la Jordanie puis aux Ligues de villages chères à Ariel Sharon au début des années $1980^{33}$. Dans ce nouveau cadre, la judaïsation non seulement peut se poursuivre mais, en plus, reçoit la légitimité de la part des représentants de ses victimes comme de ses parrains ; le confinement des Palestiniens dans des enclaves devient alors l'ersatz de leur expulsion massive inenvisageable dans les conditions actuelles. Les limites de la territorialisation de l'autonomie comme ses capacités d'exercice n'apparaissent ainsi en aucun cas comme suffisantes pour présager un exercice de souveraineté dans un partage des territoires, seul garant de la reconstruction de l'unité du peuple. Bien au delà de l'OLP comme organisation et de Yasser Arafat en tant que personne, c'est ainsi le nationalisme Palestinien lui-même, structuré sous l'égide de la centrale palestinienne ces trois dernières décennies, qui, avec l'accord de Washington, se trouve placé en situation d'échec radical. Le 13 septembre 1993, l'OLP, en la personne du président de son Comité exécutif, a ainsi, par naïveté ou trahison consciente, transformé son échec militaire et politique en abandon de la mission conférée par sa Charte. Porte-parole de la revendication des «droits nationaux inaliénables du peuple 
Palestinien ", l'OLP est, à son corps défendant, entrée dans la logique de la "bantoustanisation", en arrivant même à la défendre les armes à la main contre les derniers détenteurs de sa revendication nationale traditionnelle. Garante de l'unité du peuple Palestinien, elle a également de facto abandonné les réfugiés de la diaspora, son président ayant décidé de s'installer en zone autonome et de jouer, sous contrôle israélien, au mukhtar [l'équivalent d'un chef de quartier, de village] de Gaza, comme le considèrent maintenant avec mépris bon nombre de Palestiniens. Une "paix » dictée, en l'absence d'équité et de justice et au mépris des luttes et des processus engagés ces dernières décennies, ne pouvait dès lors déboucher que sur un État d'urgence permanent, une militarisation du régime mis en place et l'impossibilité d'envisager la construction de la démocratie. Le nombre de policiers en service dans les zones autonomes à la veille de l'entrée en vigueur d'Oslo II, initialement limité à 9.000 selon les Accords, avait été porté à 15 ou 20.000, sans compter ceux qui opéraient de facto en Cisjordanie avec le consentement d'Israël. Les arrestations arbitraires se multipliaient. Une Cour de sûreté de l'État nouvellement créée affichait des pratiques caricaturales de déni de toute justice. Tortures, fermetures de journaux, dissolution d'associations marquent la conduite de l'Autorité palestinienne décidée à coûte que coûte se plier aux exigences sécuritaires israéliennes pour se conserver les oripeaux de l'autonomie. Trop superficielles peut-être ou encore trop jeunes, les formes structurées que s'était donnée la société civile dans le cadre du Soulèvement n'ont pu que se réfugier dans les espaces abandonnés de l'Autorité, incapables d'imposer leurs exigences de participation sur la scène publique. Une part sans cesse grandissante de la population palestinienne considère dès lors que l'Autorité et sa police sont devenues une sorte de supplétif de l'armée israélienne, à l'image de l'Armée du Liban-Sud d'Antoine Lahad. Le crédit de Yasser Arafat se trouve chaque jour plus entamé auprès de sa base, même si la victoire lui est assurée aux prochaines élections du Conseil d'autonomie et de sa présidence. L'incapacité à répondre positivement aux revendications de dignité nationale et de mieux-être économique, les rumeurs de corruption de l'entourage du chef de l'Autorité, la peur d'une population se sentant à tout moment à la merci d'une police peu encline au respect de la personne, ou encore l'absence de facto de lois ont jusqu'à présent empêché de fondre les nouveaux venus dans la population: Yasser Arafat et son administration sont ainsi toujours vécus comme un leadership « de l'extérieur ».

Les islamistes à la reconquète de la Palestine eschatologique

Les métamorphoses du nationalisme palestinien opérées sous la contrainte de la dispersion et de l'occupation et toutes tendues vers la récupération raisonnée d'une souveraineté sur un territoire partagé n'ont ainsi, à l'évidence, débouché que sur la légalisation du démembrement des territoires occupés par Israël et de la dislocation du peuple palestinien soumis à une multiplication de statuts discriminants, Palestiniens des zones autonomes, Palestiniens des territoires "encore occupés », Palestiniens de Jérusalem-Est annexée, Palestiniens ayant perdu leur droit de résidence dans les territoires occupés et/ou à Jérusalem-est, Palestiniens déplacés lors de la guerre de 1967, Palestiniens réfugiés de la Guerre de 1948, Palestiniens de citoyenneté israélienne. Les manifestations festives nées du retrait israélien des villes de Cisjordanie ont, pour un temps vraisemblablement court, fait oublier la conscience qui était apparue chez beaucoup de Palestiniens que la privation de souveraineté sur leur territoire constituait bien un objectif israélien à long terme et qu'au service de cet objectif territorial fonctionnait ce que l'on pourrait appeler un "sociocide »: le bris planifié du lien social ${ }^{34}$. Alors que l'OLP avait fait de la récupération du territoire le 
fondement de son action et la base de l'unité nationale palestinienne au delà de la dispersion géographique, la désillusion territoriale inhérente au processus d'Oslo avait fait vaciller l'emprise de la centrale palestinienne sur la société palestinienne. Bien plus, ce désenchantement dessinait l'échec de l'identité nationale telle que construite sous l'égide de l'OLP et, du même coup, augmentait considérablement la capacité d'attraction de l'alternative islamiste. En Palestine, certes, à la différence des autres cas observés dans le monde arabe, l'islamisation du langage politique avait tardé à se parer des attributs de la «normalité ». En l'absence d'État palestinien, l'OLP fonctionnait tel les mouvements nationalistes arabes d'avant les indépendances. Critiquer la centrale palestinienne revenait à être perçu comme oeuvrant pour l'ennemi, d'où la difficulté rencontrée tout au long de la décennie 1980 par les islamistes palestiniens dans leur course pour la légitimité politique, idéologique et sociale. Dorénavant en charge de la gestion d'un appareil d'autonomie, l'OLP perd cette spécificité qui était la sienne et tombe dans le lot commun aux autres États de la région dont les pratiques autoritaires et les échecs leur sont immédiatement imputables. Bien plus, depuis plusieurs années déjà, dans son islamisation des référents socio-politiques, l'islamisme, loin de vouloir l'anéantissement du nationalisme, avait de fait su l'intégrer en le réinterprétant tout en s'associant à la lutte patriotique. Devant l'impossibilité de recouvrer le territoire, et tandis que le lien social se trouvait lui-même menacé, le référent religieux pouvait alors fonctionner comme un recours efficace. Et le Mouvement de la Résistance islamique (MRI) - Hamas, la principale organisation de la mouvance islamiste palestinienne ${ }^{35}$, apporte une réponse originale tant à la privation de la terre qu'au sociocide. Hamas ne gomme pas le territoire mais le place à un autre niveau que ne le fait l'OLP : ce n'est pas la terre de Palestine du début du siècle - elle n'est plus - pas plus que la Palestine appréhendée en termes de territoires partagés qui est mise en avant, mais une Palestine eschatologique. Il ne s'agit plus d'une revendication de libération immédiate. La destruction d'Israël, de toutes façons, est une «inéluctabilité coranique " ${ }^{36}$ et les moyens d'y parvenir sont multiples et permanents. Ainsi, dans le discours islamiste palestinien, la Palestine n'est pas la source de l'identité mais le lieu de son épanouissement. Dans la pratique des islamistes, c'est aujourd'hui la viabilité d'un réseau associatif - comme lieu de réponse à la désintégration sociale - qui prime, un réseau expérimenté bel et bien dans les limites de la Cisjordanie-Gaza, avec des correspondants en Israël même et dans les divers États de la région. La quête de la terre se trouvant ainsi remise à un horizon plus lointain, Hamas peut alors jouer beaucoup plus que l'OLP d'un mélange de pragmatisme et de radicalisme.

Le discours islamiste sur la Palestine L'ensemble des mouvements islamistes palestiniens vivent leur engagement dans la lutte anti-israélienne en termes d'impératif religieux de Jihâd. Hamas comme le Jihad islamique placent cette lutte aux deux niveaux du territoire et du peuple, et la pensent en termes de conflit entre le Bien et le Mal: le Jihad armé pour la libération d'une terre islamique du joug des nonmusulmans mais aussi le Jihad spirituel pour la destruction des ennemis de l'islam.

La défense du Dâr Al-Islâm Dès sa création fin 1987, le MRI a mis en avant son attachement à la terre et au peuple Palestinien : la signature de tous ses communiqués est suivie de la mention "Palestine " et Hamas se revendique officiellement comme " un mouvement palestinien spécifique » (Charte, art. 6) ${ }^{37}$. Sans renier l'arabité de la Palestine et de ses habitants, les communiqués de Hamas, cependant, mettent rarement en avant son identité arabe si l'on excepte les expressions toutes faites dans des références historiques (déclaration Balfour ou plan de partage, par exemple). Pour 
Hamas, la «Palestine est islamique de la mer au fleuve ( HMS 28, Charte art. 14), et "son islamité fait partie de la religion» (Charte, art. 27) ; Hamas s'adresse ainsi au « peuple palestinien musulman », au « peuple murâbit » et aux « murâbitûn » ${ }^{38}$ et pour lui les Palestiniens sont les descendants des «Pieux Compagnons du Prophète » et des divers conquérants musulmans, Abu cUbayda, Jacfar, Salâh Al-Dîn, Ibn Jabal ou encore Khâlid. Et c'est au " peuple musulman » ou encore aux musulmans que s'adressent les communiqués de Hamas. Bien que le terme Palestine (comme Jérusalem, sous sa forme Al-Quds comme Bayt Al-Maqdis) soit ignoré du Coran, c'est sur la base du texte prêché par Mahomet que les islamistes palestiniens déploient leur argumentaire sur la territorialisation de l'islamité à travers la bénédiction et la sanctification divines ${ }^{39}$. La Palestine, c'est « la terre bénie » vers laquelle Dieu conduit Abraham et Loth (Coran, 21, $71)$; cette terre est celle qui avait été donnée en héritage « aux gens qui avaient été opprimés » [Les Fils d'Israël] (Coran 7, 137) et celle vers laquelle Dieu accorde à Salomon le pouvoir d'ordonner au vent de souffler (Coran 21, 81) ; c'est aussi entre cette terre bénie et le Yémen qu'au temps de Salomon Dieu établit des villages (Coran 34, 18-19) ; mais c'est aussi et surtout, selon le verset le plus souvent cité, le lieu de la bénédiction divine attaché au Voyage nocturne et à l'Ascension céleste de Mahomet (Al-Isrâ wa-l-Micrâj) : "Gloire à celui qui a fait voyager de nuit son serviteur de la mosquée sacrée [traditionnellement interprétée comme étant la mosquée de la Mecque] à la mosquée très éloignée [Al-Aqsâ, qui donne son nom à la mosquée construite par cAbd Al-Mâlik Ibn Marwân après la conquête de Jérusalem sur les vestiges du Temple de Salomon] dont nous avons béni l'enceinte » (Coran 17,1) ${ }^{40}$. Cette bénédiction, en tout cas, fait que le Temple de Jérusalem constitue la direction de la prière islamique (qibla) jusque 16 mois après l'Hégire, la direction de la Kacba de La Mecque se substituant ensuite à celle de Jérusalem. "Terre bénie » de Dieu, la Palestine est également une «terre sanctifiée (ou sainte)»(Al-Ard Al-Muqaddasa), cette terre, entre Nil et Euphrate, dans laquelle les Fils d'Israël ont ordre divin de pénétrer en sortant d'Egypte (Coran 5, 21). La lecture islamique (et pas seulement islamiste) du Coran fait ainsi de la Palestine, au delà même des conditions historiques de la naissance de l'islam au 7e siècle de notre ère, une terre islamique dès le temps d'Abraham. Pour l'islam, en effet, la vision radicale de l'unité-unicité (tawhîd) de Dieu conduit à une vision occasionaliste du monde et de l'histoire. Dans une perspective musulmane, la création est un acte de bon plaisir divin qui ne saurait obéir à une " nature " qui, par une continuité intrinsèque, lierait Dieu à autre que lui-même. L'histoire ne peut ellemême être conçue en termes de continuité messianique : elle n'est qu'une succession d'événements discontinus, d'exemples de la manière dont l'unique transcendant peut se comporter quand et où il le désire. Si la révélation accordée à chacun des peuples du monde est bien unique, c'est ainsi par une même origine et non par une progression articulée de l'Histoire. Chaque prophète, en effet, ne fait que "rappeler» le pacte primordial par lequel la création reconnaît le tawhîd divin (Coran, 7,172-173). En se soumettant à Dieu, Abraham, comme tous les prophètes de la Torah et de l'Évangile, était ainsi musulman. Ce n'est qu'en altérant la Parole de Dieu que les peuples se sont éloignés de l'islam divin, devenant alors juifs ou chrétiens au sens confessionnel. Dernier prophète en date, Mahomet a été chargé de rappeler une fois encore la parole originelle de Dieu, intégralement préservée dans le Coran. Il n'est donc pas étonnant, dans une telle perspective, que la Palestine puisse être perçue comme islamique dès Abraham, qui devient l'un des archétypes du parfait musulman ${ }^{41}$. L'islamité de la Palestine ne faisant aucun doute, la territorialisation du conflit palestinien se trouve 
d'entrée de jeu replacée dans la logique islamique de la permanence du Dâr Al-Islâm, du "domaine de l'islam» (même si l'expression semble absente de la littérature de Hamas) : « Le jour où les ennemis usurpent une terre qui appartient aux musulmans, le combat devient une obligation religieuse individuelle [fard cayn] qui incombe à chaque musulman. Face à l'usurpation de la Palestine par les Juifs, il faut brandir l'étendard du Jihad»(Charte, art.15). La lettre adressée par Hamas au 19e CNP lie d'ailleurs sa création à cet impératif : «Le Mouvement de la résistance islamique est né et a mis au premier rang de ses préoccupations le Jihad total jusqu'à la libération de toute la Palestine. Il a pris la décision de faire éclater le soulèvement le 8 décembre 1987 pour réaliser cet objectif». Curieusement, la Charte, dans son article 11, donne une justification qui se veut juridique et historique d'un droit de propriété islamique : «La Palestine est une terre islamique waqf pour toutes les générations de musulmans jusqu'au jour de la résurrection et qui donc pourrait prétendre jouir de la pleine délégation de pouvoir de toutes les générations islamiques jusqu'au jour de la résurrection? Tel est son statut selon la Loi islamique, statut identique à celui de toute terre conquise par les musulmans de vive force [...]». Cette notion de Palestine, bien waqf, a de quoi surprendre puisque totalement contraire aux définitions canoniques, les références citées étant également fausses. L'auteur de la Charte fait ainsi une confusion totale entre la notion de Dâr Al-Islâm qui implique, en effet, qu'une terre conquise par les musulmans doive demeurer pour toujours "terre d'islam», et la notion de waqf, acte juridique obéissant à une loi très précise et applicable à une propriété définie. Ibn Hanbal, rapporte qu'au temps des Omeyyades, la Syrie (et donc la Palestine partie intégrante) était considérée comme Ard Al-Hijra, "terre d'asile", gagnée par le combat et protégée. Cette terre appartenait ainsi à une catégorie proche de celle du Dâr Al-Islâm; arrachée au Dâr Al-Harb, au «domaine de la guerre », son entrée dans le «domaine de l'islam » était marquée par son attribution en concessions (iqtâc). Le waqf, quant à lui, est un acte juridique par lequel le possesseur d'un bien renonce à ses droits de disposition de l'objet; le donataire n'en a ensuite qu'un usage restreint, le bien ne pouvant désormais être ni vendu, ni donné, ni partagé, ni transmis par héritage; quant au fruit de ce bien, il est, également à perpétuité, utilisé en aumône ${ }^{42}$. Bien que contredisant l'histoire et la jurisprudence islamiques, le thème de la Palestine bien waqf est périodiquement repris dans la littérature de Hamas. Dans le cas où les auteurs sont dotés d'une culture islamique plus développée que celle de l'auteur de la Charte, il est cependant abandonné au profit du développement exclusif du thème Palestine "propriété de toutes les générations de musulmans jusqu'au jour de la résurrection ${ }^{43}$. Il faut sans doute aller chercher l'origine de cette assertion dans l'argumentaire développé par le sultan Abdül Hamid II dans sa politique de refus des propositions faites par l'Allemagne du Kaiser Guillaume II et par Théodore Herzl et visant à favoriser l'installation de Juifs en Palestine ${ }^{44}$ Dans tout ce discours normatif, Hamas n'explicite jamais sa notion géographique de la Palestine. Il ne fait, en tout cas, aucune différence entre ce que l'habitude désigne comme "territoires de 48 » [Israël dans ses frontières issues de la guerre de 1948 et qui ont perduré jusqu'en 1967] et les territoires occupés en 1967. La Palestine constitue une terre islamique unique. La seule définition géographique communément présente dans la littérature de Hamas se trouve résumée dans son mot d'ordre, "Libérer la Palestine de la mer au fleuve », de la Méditerranée au Jourdain, aucune précision n'étant jamais donnée sur les frontières Nord et Sud. On peut ainsi considérer que Hamas fait sienne les délimitations de la Palestine mandataire britannique. 
16 La lutte entre le Bien et le Mal Pour Hamas, la lutte avec Israël s'inscrit également au niveau du combat eschatologique entre le Bien et le Mal : «Israël, par sa judéité et ses juifs, constitue un défi pour l'islam et les musulmans » (Charte, art.28) et il s'agit donc «d'extirper ce cancer qui mine la terre du Voyage nocturne et de l'Ascension du Prophète et menace l'ensemble $d u$ monde islamique» (HMS 13). "Depuis son usurpation de la Palestine, l'occupation israélienne a mobilisé toutes ses énergies pour travailler à se stabiliser les pieds sur notre terre sainte via la judaïsation de la terre, de l'homme et de l'identité des Palestiniens. La majeure partie de son plan est de travailler à susciter une jeune génération efféminée et engourdie, une jeune génération corrompue dans ses moeurs et sa religion. Tel est l'objectif de la judaïsation complète étudiée pour le peuple musulman sur la terre du Voyage nocturne et de l'Ascension du Prophète [...]. Et ce sur quoi l'occupation s'est concentrée, c'est la femme palestinienne musulmane [...], travaillant à diluer ses qualités par le biais de la diffusion de l'adultère, de la dépravation et autres pratiques avilissantes et abjectes des Juifs " ${ }^{45}$. Une telle historiographie rejoint tout à fait celle du Jihad islamique pour lequel « Israël est une amplification du combat entre la Vérité (Al-Haqq) et le Mensonge (Al-Bâtil) dans la vie de l'homme en ce qu'il incarne le rêve religieux falsifié d'un État, patrie du Peuple de Dieu élu, distingué dans l'humanité, portant son regard sur le monde tel le maître sur son esclave et son serviteur. Il constitue en fin de compte le summum de la lutte dirigée contre l'islam " ${ }^{46}$. Le Jihad islamique, par ailleurs, resitue la création d'Israël dans l'expansion coloniale occidentale : « Au 19e siècle, l'Occident a entrepris de se tourner vers le monde islamique (Al-Watan Al-Islâmî) afin de l'exploiter, poussé par ses pulsions d'une sensibilité croisée non éteinte et par des facteurs économiques et politiques que déterminait la nature du capitalisme montant de l'époque. Il a remarqué que seul le rempart islamique constituait l'obstacle qui lui faisait face ; c'est alors qu'il a planifié sa destruction ». L'historiographie du Jihad fait ainsi des accords Sykes-Picot et de l'abolition du califat les premières victoires de l'Occident. Israël, dans l'analyse du Jihad islamique, devient ensuite le "point d'appui de l'agression occidentale et l'instrument de sa perpétuation » dans la région. Politique de déchirement territorial sur des bases «confessionnelles»: Israël "oeuvre ouvertement à l'émergence de schismes tout autour de lui » en incitant à constituer dans la région des « micro-États confessionnels comme un État maronite, un État kurde, un État alouite et druze », mais également politique de pourrissement moral : Ahmad Sâdiq dénonce, ainsi, « la culture qu'Israël tente de diffuser parmi les fils de la umma islamique, tant en Palestine qu'à l'extérieur »; " le sexe, la liberté sans discipline, la perte des valeurs liées à la religion, la destruction de la famille, l'exacerbation du conflit entre les générations, la dévotion pour l'expérimentation sociale, etc., tout cela ne fait que mener à la spoliation culturelle, à la désintégration de l'identité musulmane et à la constitution d'une identité occidentalisée, porteuse de l'acceptation de la colonisation ». Dans sa logique de destruction d'Israël, Hamas appelle l'OLP à un retour à son principe fondateur du recours à lutte armée comme moyen de régler la question palestinienne (HMS CNP et HMS 32) et condamne, à l'avance, l'idée de création d'un gouvernement provisoire ou en exil qui ne pourrait que mettre fin à la confrontation armée (HMS 28 et HMS CNP). Dans la même ligne, Hamas demande aux « États arabes qui entourent Israël [d'] ouvrir leurs frontières aux combattants du Jihad, fils des peuples arabes et islamiques, pour qu'ils puissent jouer leur rôle et joindre leurs efforts à ceux de leurs frères de l'association des Frères musulmans en Palestine" (Charte, art. 28). Plus que la lutte armée, pourtant, le retour à la religion apparaît bien dans la littérature de Hamas 
comme l'expression privilégiée du Jihad : la restitution des droits de Dieu et de l'islam ne constituent-ils pas, d'ailleurs, l'objectif ultime de la lutte contre "lesJuifs »? Ainsi, lorsque HMS 01 affirme que pour les «masses musulmanes » en Palestine, «l'islam est la solution et l'alternative » et lorsque HMS 08 proclame qu'il n'y a "de salut et de libération que par l'islam ", Hamas met en évidence la continuité qui, à ses yeux, préside aux relations entre son engagement dans le soulèvement et ses positions antérieures qui étaient celles de l'association des Frères musulmans sur l'impératif prioritaire de réislamisation comme condition préalable à la libération. En replaçant ainsi la Palestine au niveau eschatologique de la bénédiction divine et du combat entre le Bien et le Mal, le mouvement islamiste palestinien fait de la terre non plus la source de l'identité, comme c'était le cas avec le nationalisme de l'OLP, mais le lieu naturel de son épanouissement passé et futur. L'islam devient ici le fondement de l'identité de l'individu comme de la société. Immédiatement disponible, il permet la reconstruction, dès aujourd'hui, de l'unité du groupe qui n'est plus conditionnée par le retour préalable au territoire. Tandis que la conscience se répandait parmi la population que l'occupation avait fait du bris du lien social l'instrument de sa domination et de sa pérennisation, un tel retournement dans le rapport au territoire mettait immédiatement le vaste réseau associatif, caritatif et cultuel des islamistes en situation de réponse « naturelle » immédiatement offerte pour contrer la désintégration sociale. L'idée de reconquête, n'est certes pas écartée ; les rapports de forces étant considérés, elle est simplement remise à plus tard, soumise à l'unité reconstruite de la Communauté-nation. D'ici là, en faisant du combattant mort dans la libération de la terre un martyr promis au paradis puisque tombé sur le chemin du Jihad, l'islamisme peut participer à la lutte armée sans cependant en exiger des gains immédiats dans l'ici-bas. Motivation précieuse, en situation d'infériorité radicale face à Israël, qui ne pouvait que séduire des fedayin, qui, d'ailleurs, devenaient d'autant plus facilement moudjahidin ${ }^{47}$ que l'OLP abandonnait le terrain de la confrontation militaire avec l'occupant au profit de la seule négociation diplomatique.

Les islamistes entre l'incapacité et l'interdit: le militaire et le politique Dans cette situation d'échec de l'OLP comme organisation et comme porteur de l'identité nationale, forts de cette intégration réussie du nationalisme dans leur réinterprétation islamique des référents socio-identitaires, de l'indéniable légitimité acquise dans leur participation à la lutte patriotique, de l'adéquation de leur idéologie et de leurs pratiques aux nécessités du moment mais également de l'absence de toute autre force d'opposition structurée, les islamistes auraient du, en bonne logique, se trouver à même de parachever légitimement la gestion de l'héritage de l'OLP dans les domaines militaire et politique. Rien pourtant aujourd'hui ne laisse entrevoir chez eux une capacité militaire ou politique à renverser le pouvoir de Yasser Arafat et à remettre en question le processus de Washington. Les appareils militaires de Hamas et du Jihad islamique ne sont, en effet, constitués que d'un nombre restreint d'individus à l'armement des plus rudimentaires. En dehors d'opérations sporadiques à objectif limité, les Kataëb Ezzedine Al-Qassam de Hamas et les Forces Qasam du Jihad sont quasi impuissantes face à une armée israélienne hyper-sophistiquée comme face à la police palestinienne de plus en plus nombreuse. Tout laisse penser que, même dans l'hypothèse d'un attentat réussi contre Yasser Arafat, les islamistes n'auraient pas les capacités de prendre le pouvoir si tant est qu'Israël leur en laisserait l'opportunité. L'option militaire généralisée adoptée par les islamistes face à l'Autorité et à l'État hébreu ne déboucherait vraisemblablement que sur une sanglante guerre civile 
palestinienne dont l'OLP, par ses soutiens extérieurs et le nombre de ses éléments armés, sortirait militairement vainqueur. Dès aujourd'hui, arrestations massives et éliminations ciblées menées tant par Israël que par l'Autorité palestinienne visent à éradiquer tout embryon de puissance militaire islamiste stable. Aujourd'hui donc incapable et interdit tout à la fois de prendre le pouvoir, l'islamisme palestinien se trouve également sommé de s'éloigner de la violence par une part grandissante de sa propre base épuisée par bientôt trente années d'occupation et huit années de soulèvement. Conviction est, en effet, partagée par le plus grand nombre (partisans comme opposants de l'autonomie actuelle, nationalistes comme islamistes) que l'accord de Washington appartient à l'ordre des faits et aucune force organisée ne semble pouvoir ni vouloir mobiliser les énergies nécessaires au renversement de la situation. Assoiffée de "normalité » quotidienne, la population de façon générale se réfugie dorénavant dans la sphère du bien-être privé loin de toute violence. Consommer, trouver un emploi, assurer une bonne éducation à ses enfants, telles sont les aspirations du moment parfois monnayées en termes d'émigration ou, phénomène nouveau, de demande de la nationalité israélienne pour un nombre croissant de résidents de Jérusalem annexée. Les islamistes, en ce qui les concerne, conjuguent aspiration au bien-être et résolution à renforcer leur identité musulmane à coup de prières, de pratiques surérogatoires et de lectures intensives du turâth (héritage) traditionnel. Nul, islamistes comme nationalistes, ne pense sérieusement à l'éventualité d'une nouvelle intifada ce qui n'exclut bien évidemment pas les risques d'émeutes de la faim, de manifestations violentes mais sporadiques, ou encore d'opérations de guérilla menées par de petits groupes de plus en plus autonomes. Aujourd'hui unique acteur palestinien de la scène militaire anti-israélienne et néanmoins contenu et appelé à renoncer à la lutte armée, l'islamisme ne semble pas, à court terme, en meilleure posture politique. En dépit des frustrations grandissantes de la population palestinienne et de son indéniable capacité de mobilisation, la croissance de l'islam politique semble, en effet, marquer un temps d'arrêt. En 1994-1995, les indicateurs disponibles font ainsi état d'une fourchette certes large mais stable, oscillant entre les 15-25\% d'après les sondages établis par le CPRS (Center for Palestine Research and Studies) de Naplouse (une hypothèse basse établie par un institut proche du Fath sur un échantillon censé renvoyer à l'ensemble d'une population dont une large part accorde encore son suffrage à l'Autorité établie quelqu'elle soit, aujourd'hui encore le Fath) et les 45-65\% résultant des élections estudiantines ou syndicales (une hypothèse haute sur la base d'échantillons marqués par l'âge et l'appartenance à certaines catégories sociales ou professionnelles). En dépit de son indéniable emprise, l'islamisme a échoué à s'attacher l'ensemble des oppositions à l'accord de Washington par intégration ou catalyse (échec du "groupe des Dix » de Damas et maintien au sein du Fath de son importante opposition interne). Elément incontournable de la scène politique, certes, et rival du Fath en terme de soutien militant, l'islamisme palestinien n'a de toutes façons pas la possibilité de traduire institutionnellement sa puissance de mobilisation sur une scène politique contrôlée par l'OLP. Fin 1995, les conditions mises par l'Autorité palestinienne à la création d'un parti politique islamique ne pouvaient, en effet, conduire qu'à publiquement formaliser la renonciation à la lutte anti-israélienne et la reconnaissance de la légitimité du processus de Washington, ce qui revenait ainsi à vider le projet politique islamiste d'alors de tout sens.

18 L'acquiescement des islamistes à l'injonction de repli sur le social et le religieux. Leur expérience quiétiste dans le passé Dans un tel contexte, en dépit de sa vocation à 
légitimement assumer l'héritage de l'OLP et du nationalisme dans les domaines tant militaire que politique, l'islamisme palestinien se trouve de plus en plus enclin à renouer avec des pratiques de type fondamentaliste exclusivement centrées sur le religieux et le social. Un tel choix, s'il crée bien une rupture avec les engagements récents de Hamas, ne constitue cependant pas une trahison ni de son histoire ni de ses idéaux. La tradition idéologique et politique des Frères musulmans, telle qu'illustrée par exemple dans la Jordanie voisine, les conduit avant tout, en effet, à revendiquer de la part de l'État en place sa reconnaissance de leur légitimité à être et à agir dans un partage des tâches : à l'État le «Politique » avec la Défense et les Affaires étrangères ; aux Frères, la société avec le culte, la moralité et l'éducation; pour chacun, la possibilité de développer ses assises économiques. Dans le champ palestinien, une sorte d'accord tacite avait ainsi régi pendant une décennie entière (1977-1987) les rapports entre Israël et les Frères musulmans (alias le « Rassemblement islamique » de Chaykh Ahmad Yasin, guide des Frères et fondateur de Hamas à Gaza, les différents «blocs islamiques » dans les universités de Gaza et de Cisjordanie et la multitude d'associations caritatives et cultuelles). En s'abstenant de toute intrusion dans le champ de la lutte active anti-israélienne, les Frères musulmans s'étaient acquis de la part de l'occupant une entière liberté d'agir dans l'établissement, le financement et le fonctionnement de leur réseau caritatif. Ce ne fut que sous la pression des événements, l'intifada en tant que rejet global de l'occupation par l'ensemble de la population, que, fin 1987, les Frères avaient laissé se créer le Mouvement de la résistance islamique pour, plusieurs mois plus tard seulement, le reconnaître comme leur «bras actif » et ainsi entrer dans la lutte anti-israélienne. Dans le domaine idéologique, plus que la lutte armée adoptée de façon très récente par le mouvement, le retour à la religion apparaît bien dans la littérature de Hamas comme l'expression privilégiée du Jihad : «l'islam est la solution et l'alternative » avait ainsi inscrit le mouvement dans son premier communiqué de l'intifada.

Des pratiques diverses et contradictoires! En soumettant la reconquête de la Palestine à la reconstruction de l'unité de la communauté, les islamistes se donnent une capacité de négociation sur le quotidien politique et militaire d'autant plus forte que le pérenne est considéré comme sauvegardé via leur propre renforcement institutionnel. Tout leur discours normatif sur l'illégitimité de principe d'Israël et l'inéluctabilité de sa destruction peut, dès lors, se traduire au jour le jour par des pratiques diverses sinon contradictoires, y compris la capacité à envisager une coexistence plus ou moins transitoire avec l'État d'Israël : en Galilée, les islamistes, par ailleurs gestionnaires de nombreuses municipalités, ne sont-ils pas détenteurs de la citoyenneté israélienne? Hamas, à de nombreuses reprises, a ainsi cherché à se faire reconnaître comme interlocuteur par Israël, visant par là à s'imposer également à l'Autorité palestinienne sans entrer, selon le mouvement lui-même, dans les termes israéliens. Le 13 décembre 1993, par exemple, le général Doron Almog, commandant en chef de l'armée israélienne dans la Bande de Gaza, avait affirmé qu'il avait rencontré les semaines précédentes "d'éminents leaders de Hamas ». Cette déclaration avait été démentie le lendemain dans un communiqué du mouvement. Quelques semaines plus tard, cependant, le Dr. Mahmud Al-Zahhar, porte-parole officieux du mouvement à Gaza, déclarait: "Nous avons entendu dire que des officiers de l'armée ont rencontré des leaders de Hamas avant le bannissement [de Marj Al-Zuhur, décembre 1992]; vraiment, je n'ai aucune objection concernant de telles rencontres " ${ }^{48}$. Le 6/11/94, à l'extérieur des territoires occupés cette fois, Ibrahim Ghawsheh, porte-parole officiel de Hamas installé à Amman, 
déclarait que son mouvement n'entreprendra pas de pourparlers directs avec Israël mais qu'il était prêt à négocier via un "troisième parti " "telle que la Croix rouge internationale ». De même façon et à pareille époque, Chaykh Jamil Hamami, importante personnalité proche du mouvement à Jérusalem, avait lancé un appel au dialogue avec Israël en échange de la libération des prisonniers palestiniens. De telles propositions, si elles pouvaient sembler contredire la rigidité du discours normatif, allaient, en tout cas, dans le sens de l'opinion publique de l'époque. Selon un sondage effectué par le CPRS de Naplouse les 17-19/11/1994, à la question de savoir s'il convenait que Hamas ouvrît le dialogue avec Israël, $44,6 \%$ des sondés se réclamant du mouvement répondirent, par l'affirmative. De tels contacts, de toutes façons, existaient déjà depuis plusieurs années, comme en témoignent les déclarations déjà citées, même si un débat existait au sein des autorités israéliennes en la matière. La réflexion menée au sein de Hamas dépassait cependant le débat de simples contacts avec les Israéliens et avait déjà abordé celui d'une "coexistence pacifique " plus ou moins transitoire. Les déclarations normatives, rappelons-le une fois encore, laissent place à de nombreuses ambiguïtés. Ainsi, si HMS 04 se montrait résolument hostile à cette idée, HMS 24 semblait plutôt considérer qu'elle aurait été la bienvenue mais que la violence israélienne l'avait tuée: "Qu'ils sachent, en toute netteté, que l'idée de coexistence entre notre peuple palestinien occupé et leur entité intruse est devenue une idée morte ». Sans doute faut-il lire le terme de « coexistence » dans le sens préconisé par la Charte, art. 6 et 31, celui de la coexistence des 3 religions " célestes" à l'ombre de l'islam, cet assujettissement, dont les clauses sont développées par la Charte, constituant la condition indispensable à la bonne entente entre religions. Le " non à la paix avec l'entité sioniste » de HMS 08 renvoyait à son exégèse du Coran 7, 167 : « Dieu, en ce qui les [les juifs] concerne, n'a pas écrit de paix sur la terre ", exégèse qui ne fait que renforcer le refus de principe de la reconnaissance de l'État d'Israël. Et nombreuses ont été les condamnations prononcées par Hamas de toute négociation et reconnaissance. Le Chaykh Ahmad Yasin, pourtant, fondateur et guide spirituel de Hamas, avait déclaré dès 1990 : «Nous ne voulons pas la fin de l'État d'Israël, et nous sommes prêts à négocier avec ce pays à condition qu'il reconnaisse le droit du peuple palestinien à vivre en paix et librement sur sa terre ». En 1993-1994, à un moment où les opérations militaires montées par les Kataëb Ezzedine Al-Qassam s'intensifiaient, les signes se sont multipliés d'une capacité de Hamas à envisager une coexistence plus ou moins transitoire avec l'État d'Israël. Dans une déclaration rapportée par Associated Press le 6.11.94, Ibrahim Ghawsheh, par exemple, avançait que les Kataëb arrêteront toute attaque contre les civils israéliens quand « l'armée israélienne, les colons et les unités camouflées arrêteront les assassinats de civils palestiniens»; il précisait, cependant, que cet engagement n'engagera pas Hamas à cesser ses attaques contre les installations militaires israéliennes «jusqu'à ce que l'occupation israélienne de nos terres cesse ». Le 14 mars 1993, Muhammad Nazzal, représentant de Hamas en Jordanie, avait été beaucoup plus loin puisque, tout en déclarant que Hamas était hostile au processus de négociations en cours, il affirmait que son mouvement était «prêt à établir un État palestinien intérimaire sur toute partie de la Palestine évacuée par Israël ou libérée par la force ». «Un tel État constituera une étape intermédiaire sur la voie de la récupération de toute la Palestine», ajoutait-il tout en précisant que ce développement serait néanmoins "conditionné par la non-reconnaissance de l'État d'Israël ». Cette déclaration avait alors coïncidé avec des rencontres entre responsables de Hamas et diplomates notamment américain, britannique, allemand, italien et 
espagnol à Amman et à Khartoum. Cette déclaration était alors passée quasi inaperçue. Un an plus tard, une autre déclaration, faite cette fois-ci par Musa Abu Marzuq, chef du bureau politique de Hamas, et publiée dans l'hebdomadaire du Front d'action islamique jordanien, Al-Sabîl, le 19/04/94, avait eu un grand retentissement. Faite à l'occasion de menaces israéliennes proférées contre le mouvement et la Jordanie suite à la revendication émise le même mois depuis Amman par les Kataëb Al-Qassam de deux opérations militaires menées en Israël et ayant fait une douzaine de morts israéliens, la déclaration insistait sur le fait que la Palestine constitue le lieu exclusif de la lutte armée de Hamas: «Le mouvement Hamas a limité son combat à la Palestine en sa qualité de terre occupée. Le mouvement s'est engagé délibérément à y lutter par tous les moyens disponibles ». Et Abu Marzuq soulignait que les activités de Hamas hors Palestine [et donc en Jordanie] n'étaient que "politiques et médiatiques »: "Nous ne pratiquons pas l'action militaire de l'extérieur ». Le périodique reproduisait également un communiqué du Bureau politique du mouvement selon lequel «toute paix dans la région doit être bâtie sur le retrait israélien des territoires occupés et l'organisation d'élections libres en Cisjordanie et à Gaza pour choisir les représentants du peuple palestinien qui décideront des prochaines étapes et de l'avenir de la cause ». Abu Marzuq commentait ensuite cette déclaration : «En tant que mouvement de résistance, nous considérons qu'au cas où le gouvernement de l'ennemi souhaiterait sortir de l'impasse dans laquelle il se trouve, cela ne pourra se faire en imposant une reddition au peuple palestinien. Mais nous disons qu'il peut y avoir un accord de paix ou une armistice pour sortir de l'imbroglio régional et sortir de la crise. Les résolutions des Nations-Unies et du Conseil de sécurité ont considéré que la Cisjordanie, Gaza et Jérusalem étaient des territoires occupés que possédait et sur lesquels vivait le peuple palestinien. Si Israël souhaite que la résistance cesse dès à présent, les étapes suivantes doivent être respectées : 1 - Retrait des forces israéliennes de la Cisjordanie, de Gaza et de Jérusalem ; 2 - démantèlement des colonies ; 3 - dédommagement pour les pertes et les victimes de l'occupation; 4 - organisation d'élections libres qui permettent au peuple palestinien de choisir sa direction. [...]. Si le mouvement emporte ces élections, il défendra la position militante qui est la sienne. En revanche, s'il est minoritaire, il exprimera alors son point de vue en toute liberté. Nous respectons le point de vue de la majorité élue. [...]. Nous ne sommes pas opposés à ce que la Cisjordanie, Gaza et Jérusalem soient placés sous le contrôle d'une force internationale, d'une police palestinienne ou de l'administration arabe qui les gouvernait avant l'agression de 1967 ». Ahmad Bahr, un autre responsable du mouvement enseignant à l'Université islamique de Gaza, se déclarait alors partisan lui aussi de la libération de toute partie de la Palestine, à condition, précisait-il, "de ne pas reconnaître Israël et de ne pas renoncer au reste de la terre de Palestine ». Devant le trouble suscité dans les rangs de Hamas par ses propres déclarations, Abu Marzuq précisait, le 21 avril, que l'offre de Hamas ne portait que sur "une trêve »: Hamas est "prêt à faire la trêve avec les occupants conformément aux principes et aux intérêts islamiques ", ajoutant que son mouvement « demeurera attaché à son programme, ne renoncera pas à la terre, ni ne reconnaîtra l'ennemi sioniste ». Un communiqué officiel du mouvement publié le même jour ${ }^{49}$ expliquait que les déclaration d'Abu Marzuq «ne constituaient pas une reconnaissance par Hamas de l'entité sioniste ni une acceptation de la résolution 242 ». $\mathrm{Au}$ printemps 1995, cImad Faluji, rédacteur en chef d'Al-Watan, l'organe officieux du mouvement à Gaza, tenait devant moi le même langage : Hamas est prêt à envisager une hudna, un cessez-le-feu de «10, 20 ans ou plus » avec Israël, à la condition d'un 
retrait complet et réel de l'ensemble des territoires occupés en 1967, de la suppression des colonies et de l'organisation d'élections législatives palestiniennes. Il n'est donc pas question de signer la paix ni de reconnaître la légitimité d'Israël, ce qui, selon lui, irait à l'encontre des principes coraniques, mais d'établir un armistice débouchant sur « une situation comparable à celle qui a existé toutes ces dernières années entre la Syrie et Israël ». Et Chaykh Nafidh cAzzam, un des responsables du Jihad islamique à Gaza, tenait à pareille époque des propos fort semblables. Depuis le printemps 1995 et en dépit de l'absence de concessions israéliennes allant dans le sens des exigences posées par les islamistes, une opération de désolidarisation de l'aile politique de Hamas dans les territoires autonomes vis à vis de l'appareil militaire du mouvement est en train de s'opérer dans la logique d'un cessez-le-feu entre zones autonomes et Israël réclamé par l'Autorité palestinienne sous pression israélienne. Ainsi, même si l'opération-suicide menée à Gaza le 25 juin 1995 contre des soldats israéliens avait été revendiquée par les Kataëb, Al-Qassam, puis par le bureau d'information de Hamas à l'extérieur, un troisième communiqué, signé des Kataëb mais attribué au commandement politique de Hamas dans les territoires autonomes, a nié toute implication du mouvement. Un mois plus tard, l'explosion de Ramat Gan du 24 juillet 1995 n'a, quant à elle, jamais fait l'objet de revendication authentifiée ni par Hamas ni par les Kataëb, bien que ses instigateurs supposés, arrêtés en août et également responsables de l'explosion de Jérusalem du 21 août 1995 (qui, elle, a été revendiquée par le bureau de Hamas à Damas), aient été de jeunes responsables de la branche étudiante du mouvement à Naplouse. Ainsi, depuis plusieurs mois maintenant, le commandement politique de Hamas dans les territoires autonomes s'en tient-il à un engagement tacite à ni entreprendre ni revendiquer d'opérations militaires menées dans les zones autonomes ou à partir d'elles. Pareille position va donc au-delà des déclarations déjà mentionnées qui exigeaient un retrait total israélien préalable même si le mouvement se refuse encore à consigner un tel engagement dans un texte.

Leur disposition à un modus-vivendi avec l'Autorité palestinienne Si la guerre permanente avec Israël peut ainsi être reconsidérée par les islamistes, les rapports avec l'Autorité palestinienne sont également susceptibles de trouver une normalité exempte de violence, si telle est la volonté de la partie au pouvoir. Le mouvement, en ce domaine, met en avant l'interdit islamique traditionnel de la fitna, la lutte entre musulmans, la guerre civile intra-palestinienne. Face à la répression dont ils ont fait l'objet, c'est, en effet, une extrême retenue qui a caractérisé l'attitude adoptée par Hamas et le Jihad islamique face à l'Autorité après les événements de novembre 1994 au cours desquels la police palestinienne, ayant ouvert le feu au sortir d'une mosquée de Gaza sur une foule de manifestants islamistes, avait tué seize fidèles, comme après les internements de masse ou encore les attentats aux responsables non identifiés menés dans les territoires autonomes contre de hauts dirigeants du Jihad (Hani Abid en novembre 1994 et Mahmud Khawaja en mai 1995) ou des Kataëb Al-Qassam (explosion de Gaza / Chaykh Radwan en avril 1995). A aucun moment, le mouvement islamique ne s'est ainsi engagé sur la voie de la confrontation frontale et généralisée avec l'Autorité. Bien au contraire, lorsqu'il s'agissait d'affaires couvertes par l'Autorité mais sans lien avec le cadre israélien d'autonomie, le mouvement n'a jamais hésité à s'impliquer dans leur gestion. Ainsi Chaykh Hamid Al-Bitawi, président de la Ligue des Ulémas de Palestine et ancien banni de Marj Al-Zuhur en décembre 1992 pour ses activités liées à Hamas, a-t-il accepté en janvier 1995 le poste de président de la Cour d'Appel islamique récemment créée par Yasser Arafat. C'est donc dans ce contexte qu'il convient 
d'appréhender la position de Hamas sur sa participation à d'éventuelles élections d'un Conseil d'autonomie. Cette participation, certes, a fait l'objet de déclarations contradictoires en 1993-1995. Chaykh Ahmad Yasin témoignait de son traditionnel pragmatisme en écrivant fin 1993: "La question de tenir des élections se pose aujourd'hui sur la scène palestinienne, les islamistes se partageant entre ceux qui sont favorables à y entrer et ceux qui s'y opposent; en ce qui me concerne, mais Dieu est le seul savant, y entrer me semble meilleur que s'en abstenir, à la condition que le conseil soit doté de prérogatives législatives; nous sommes en effet opposés à ce qui se passe dans la rue, alors pourquoi ne pas manifester notre opposition au coeur même de l'institution législative qui deviendra, de droit, dans l'avenir l'instance de représentation du peuple palestinien ? [...] ». Une telle participation "réaffirmera la force de la présence islamique sur la scène et interdira son amoindrissement dans l'isolement ». Ibrahim Ghawsheh affichait, quant à lui, une ligne plus dure, affirmant, le 6 janvier 1994 alors qu'il négociait à Damas au nom de Hamas l'opposition des 10 organisations hostiles à l'accord de Washington, que les propos de Chaykh Yasin avaient été déformés et que Hamas ne participera pas à d'éventuelles élections sur l'autonomie. «En revanche, ajoutait-il, Hamas continuera à participer à des élections n'ayant pas de caractère politique ", position identique, en la circonstance, à celle de Mahmud Al-Zahhar, porte-parole officieux de Hamas à Gaza, qui affirmait: "Nous participerons à toute élection qui n'entretient aucun lien avec l'autonomie ». Fin 1995, alors que Hamas a officiellement refusé de participer aux élections, tout indique que rien ne sera fait de la part des islamistes pour faire échouer le processus. Certes la création d'un parti islamique émanant de Hamas, à l'image du Front de l'action islamique devanture politique en Jordanie de l'Association des Frères musulmans, avait été envisagée par certains. En l'absence de légitimité du régime d'autonomie comme d'une loi sur les partis, garante de la liberté d'expression jusque dans la critique des fondements de cette autonomie, le mouvement islamique, Jihad compris, s'est cependant refusé d'entrer dans un jeu qui, selon eux, ne servirait que l'Autorité. Une certaine unanimité s'était, d'ailleurs, dégagée sur cette position dès l'été 1995, au delà même de la diversité de certaines déclarations. Début août 1995, par exemple, Yasser Arafat avait échoué à créer une scission au sein de Hamas en suscitant la fondation par Muhammad Abu Dhan, un ancien du mouvement, d'un Parti de la voie nationaleislamique; l'annonce de cette fondation n'avait eu aucun écho. Dans la logique d'une participation distanciée à ces éventuelles élections d'un Conseil d'autonomie, en l'absence d'un véritable parti islamique défenseur des positions de Hamas, c'est donc vers des candidats réputés indépendants mais proches du mouvement que se dirigeront vraisemblablement les voix islamistes. Pendant trente ans, le peuple palestinien, sous égide de l'OLP, a construit son identité nationale sur la base de la récupération d'une souveraineté sur un territoire partagé. En cultivant la " bantoustanisation », l'accord de Washington a consacré l'échec idéologique, politique et militaire de la centrale palestinienne tout en l'imposant comme Autorité. Globalement délégitimée mais détentrice de la force, l'Autorité palestinienne a pu mettre à profit la lassitude de la population et la menace de la guerre civile pour interdire à ses seuls compétiteurs légitimes actuels, les islamistes, l'accès au politique et le maintien de leur engagement militaire. Ce retour forcé pour l'islamisme de l'hypothèse "révolutionnaire » au néofondamentalisme ${ }^{50}$, quasi acquis dès aujourd'hui, se traduira à n'en pas douter par une emprise sociale accrue, d'autant plus facilement que la population, privée de libération nationale comme, selon toute vraisemblance, de démocratie réelle, trouvera dans la 
religion de nouvelles raisons d'endurer et d'espérer. Aucune concession israélienne de fond n'étant à attendre, l'illégitimité de l'Autorité palestinienne auprès de sa base sera appelée à s'amplifier dans ces «bantoustans d'Allah» qu'Israël est en train de mettre en place. Contrairement à leurs prédécesseurs sud-africains, en l'absence de richesses du sous-sol et de la possibilité d'un chantage à la main d'oeuvre désormais remplacée par une force de travail en provenance d'Europe centrale ou du sud-est asiatique, confrontés à un soutien politique international unanime accordé à Israël, ces nouveaux bantoustans se retrouvent, de fait, incapables de faire exploser à moyen terme le système politique ségrégationniste qui les contrôle. Les colonies israéliennes ont déjà verrouillé les points d'eau les plus importants, le couvert végétal le plus riche ainsi que les zones de contact avec les voisins jordanien et égyptien sans oublier les espaces aérien et maritime. Par fidélité à la Déclaration universelle des Droits de l'Homme, il faudra bien qu'un jour la communauté internationale se décide à désigner et à dénoncer comme ségrégatives des pratiques dès aujourd'hui observables et en constant développement, pour qu'enfin les conditions d'une "paix juste et durable" soient requises et que soit mis fin à une prétendue «solution » qui ne fait que temporiser sans s'attaquer au fond de la question, le partage et la souveraineté sur les territoires respectifs.

\section{NOTES}

1. Maxime Rodinson, «Israël, fait colonial », Les Temps modernes, $n^{\circ} 253$ bis, 1967, pp. 17-88. Et Rodinson poursuit : « Il s'agit là de faits. Pour ce qui est des termes, il me semble que celui de processus colonial convient fort bien ».

2. Jean-François Legrain, « De la faiblesse de l'OLP, de la sincérité d'Israël », Le Monde, 10 septembre 1993 ; Edward W. Said, Peace and Its Discontents. Gaza-Jericho 1993-1995, London, Vintage, 1995.

3. Sur ces problèmes, voir Alain Gresh, OLP. Histoire et stratégies vers l'État palestinien, Paris, 1983 ; Spag-Papyrus ou encore Robert Vitalis, « The Palestinian-Israeli Conflict : Options and Scenarios for Peace », in Elizabeth W. Fernea and Mary E. Hocking (eds.), Israelis and Palestinians. The Struggle for Peace, Austin, University of Texas Press, 1992, pp. 285-313. Pour les documents cités, voir Xavier Baron, Proche-Orient, du refus à la paix. Les documents de référence, Paris, Hachette, 1994.

4. Jean-François Legrain, « Le pouvoir en Cisjordanie : un combat à quatre », Bulletin du CEDEJ, $\mathrm{n}^{\circ} 23$, 1er trimestre, 1988, pp. 149-182.

5. Cité par Alain Gresh, op. cit., p. 123.

6. Ibid., p. 155.

7. Ibid., p. 132.

8. Cf. Xavier Baron, op. cit., p. 165.

9. Voir le témoignage de Mahmoud Abbas (Abou Mazen), Sd. (1995), Le chemin d'Oslo, Paris, Edifra.

10. Middle East Watch, A License to Kill. Israeli Undercover Operations Against

"Wanted" and Masked Palestinians, Human Rights Watch, New York, 1993. Durant la 
même période, 70 Israéliens avaient été tués, preuve de l'élévation générale du niveau de violence.

11. C'est, en effet, en terme de judaïsation qu'il convient d'aborder la colonisation, dispositif central mais non exclusif de l'appropriation de la terre par le sionisme. Colonisation juive et non seulement israélienne puisque, comme le fait remarquer Israel Shahak, Report, $\left.n^{\circ} 154,12 / 05 / 95\right)$ en Israël comme dans les territoires occupés aucun non-juif, même citoyen israélien, ne saurait profiter des terres massivement confisquées (92\% en Israël, 70-73\% dans les territoires occupés), confiées à la « Direction des terres d'Israël », organisme affilié au Fonds National Juif et, par là, à l'Organisation Sioniste Mondiale. Ces terres, en revanche, sont disponibles pour tout juif dans le monde même dépourvu de la citoyenneté israélienne.

12. Israel Shahak, Report, $\mathrm{n}^{\circ} 149$.

13. Report on Israeli Settlement, vol. 3, november 1993, p. 3. Des chiffres différents, favorables au gouvernement israélien, sont donnés par l'AFP, 12/08/93 : sur la même période, 2.510 unités de logement ont été entamées, contre 6.440 durant les neuf mois précédents sous le gouvernement Shamir ; la construction sur fonds publics a également diminué avec $61 \%$ du total des mises en chantier contre $84 \%$ lors des neuf mois précédents.

14. Selon AIC. Cf. Alternative Information Center, Israeli Settlement in the West Bank. Past, Present and Future, Jérusalem, n 20, 1995.

15. Israel Shahak, Report $n^{\circ} 154$. Les chiffres concernant Gaza diffèrent de façon considérable selon les sources et parfois même au sein de mêmes sources selon les moments : selon la radio israélienne, 11/04/95, citant des chiffres de Yesha, le nombre de colons y serait passé de 5160 en décembre 1993 à 6 215, un an plus tard; Peace Now, cité in Journal of Palestine Studies, n 91, Spring 1994, p. 127, en 1993 ne comptait à Gaza que 3810 colons.

16. Report on Israeli Settlement, vol.5, $\mathrm{n}^{\circ} 4$, july 1995.

17. Report on Israeli Settlement, vol.4, $\mathrm{n}^{\circ} 1$, february 1994.

18. Selon AIC, op. cit., p. 11.

19. Blandine Destremeau, «Israël-Palestine : séparation et pratiques de l'espace ou l'appropriation identitaire du territoire ", Maghreb-Machrek, n¹50, octobre-décembre 1995.

20. Enquête menée par Bernard Sabela, citée in PHRIC, (Palestine Human Rights Information Center, « East Jerusalem Indicators Relating to Israeli Policies », 07/06/94, rep. in Journal of Palestine Studies, $n^{\circ}$ 93, Autumn 1994 : pp. 119-120. Il convient, par ailleurs, de rappeler qu'au terme de sept années d'absence de la ville, à l'étranger ou en dehors des limites municipales, ou encore en cas d'obtention d'une autre nationalité ou d'un droit de résidence permanent dans un autre pays, les Palestiniens de Jérusalem perdent définitivement leur droit de résidence dans la ville sainte.

21. Markaz Abhâth Al-Arâdî, Al-Nashâtât Al-Istîtâniyya wa Musâdarat Al-Arâdî fî-l-Diffa Al-Gharbiyya (Les activités de colonisation et d'expropriation des terres en Cisjordanie), Jamciyyat Al-Dirâsât Al-cArabiyya, Jerusalem, 24 janvier 1994.

22. $1 \mathrm{Ha}$ fait environ 10 dunums et 1000 dunums équivalent donc à à peu près $1 \mathrm{Km} 2$. La Cisjordanie couvre 5375000 dunums, Jérusalem-est 72000 dunums et la Bande de Gaza 365000 dunums.

23. Cité dans JMCC (The Jerusalem Media and Communication Centre), Beg, Borrow or Steal : Israeli Settlement in the Occupied Palestinian Territories, Jerusalem, 1991. 
24. Rapport établi par René Fleber de la commission des droits de l'homme des Nations unies cité in Palestine Times, september 1995.

25. Yediot Aharonot, 22/01/95 cité in Report on Israeli Settlement, vol. 5, $\mathrm{n}^{\circ} 2$, march 1995.

26. Report on Israeli Settlement, vol. 5, $\mathrm{n}^{\circ} 5$, september 1995. D’autres estimations font état de 20 à $25 \%$ de la superficie.

27. Alain Gresh, « Paix piégée au Proche-Orient », Le Monde diplomatique, décembre 1995 ; Jan de Jong, « Israël, maître de la Cisjordanie », Le Monde diplomatique, décembre 1995.

28. Comme le souligne Geoffrey Aronson in Report on Israeli Settlement, vol.5, $\mathrm{n}^{\circ} 6$, November 1995.

29. Israël consommait jusqu'à présent $82 \%$ des eaux pompées en Cisjordanie ; la part destinée aux Palestiniens devrait passer de 18 à 23\%, un forum tripartite (États-unis, Israël, OLP) étant appelé à examiner la question.

30. Patrice Claude, in Le Monde, 22/07/95.

31. Traduit de la version anglaise diffusée par le Israel Information Service Gopher (http: //www.israel.org/israel-info/titles.cgi).

32. Jerusalem Post, 25/05/94. Parmi les membres du groupe, on trouve également en 1995 l'ancien speaker de la Knesset Shlomo Hillel, quelques ministres comme Ya'acov Tsur et Shim Shetreet ou encore le général et ancien chef d'état-major Dan Shomron. Voir aussi Jong, 1995.

33. Leitmotiv d'Israël Shahak; voir par exemple, son « How Israel Will Control the West Bank and Gaza », in Middle East International, 17/11/95.

34. Le terme m'a été suggéré par Jean Métral.

35. Sur cette mouvance islamiste voir Ziad Abu Amr, Islamic Fundamentalism in the West Bank and Gaza. Muslim Brotherhood and Islamic Jihad, Indiana University Press, 1994 ; Jean-François Legrain, « Hamas, legitimate heir of Palestinian nationalism ? » in John Esposito (ed.), Political Islam in Middle East, Washington, United States Institute of Peace, à paraître ; Ahmad Rashad, Hamas : Palestinian Politics with Islamic Hue, United Association for Studies and Research, Annandale, VA, 1993

36. Selon l'expression utilisée par l'un des guides spirituels de la mouvance du Jihad islamique, Chaykh Ascad Al-Tamîmî, Sd., Zawâl Isrâ'îl, Hatmiyya Qur'âniyya (La destruction d'Israël, une inéluctabilité coranique), Beyrouth.

37. On trouvera la reproduction de la version de la Charte diffusée dans les territoires occupés et sa traduction française intégrale dans Jean-François Legrain, Les Voix du soulèvement palestinien, 1987-1988, Le Caire, CEDEJ, 1991, dans lequel figurent les références exhaustives des thèmes développés ci-après ainsi que les textes traduits intégralement. HMS suivi d'un numéro renvoie à la série numérotée des communiqués de Hamas. Sur la naissance du mouvement, voir Jean-François Legrain, « Les islamistes palestiniens à l'épreuve du soulèvement », Maghreb-Machrek, $\mathrm{n}^{\circ} 121$, juillet-aoûtseptembre 1988, pp. 5-42.

38. Le murâbit est celui qui pratique le ribât, c'est à dire la défense du territoire de l'islam par les armes et la vie de piété.

39. Le discours de Hamas en la matière se trouve très bien résumé dans Salâh AlKhâlidî, Haqâ'iq Qur'âniyya Hawla-l-Qadiyya Al-Filastîniyya (Vérités coraniques à propos de la cause palestinienne), Londres, coll. Filastîn Al-Muslima, 1994. 40. Traduction de Denise Masson, coll. La Pléiade, Paris, Gallimard, 1967. En optant pour « son enceinte », Denise Masson se range derrière l'interprétation restrictive de 
l'arabe ; une autre traduction est possible avec « le pourtour », interprétation adoptée par les islamistes palestiniens.

41. Jean-François Legrain, « La religion selon l'islam », Revue de l'Institut Catholique de Paris, $n^{\circ} 19$, juillet-septembre 1986, pp. 6-9.

42. Christian Décobert, Le mendiant et le combattant. L'institution de l'islam, Paris, Le Seuil, 1991, pp. 19-22, 265 ss, 280 ss.

43. C'est, par exemple, le cas de la lettre adressée par Hamas au 19ème CNP (10/11/88) et de son communiqué $33(21 / 12 / 88)$ pour la seule première année du mouvement. J'ai eu l'occasion de montrer dans Les voix du soulèvement, en quoi la Charte constituait une sorte d'apax, ses thèmes ou leur traitement ne recouvrant pas toujours ceux abordés par les communiqués périodiques du mouvement à la même période. Certains membres de Hamas n'ont pas hésité devant moi à mettre en cause le caractère de référence intouchable de la Charte, affirmant qu'elle n'était que l'élaboration individuelle d'un jeune auteur peu cultivé et originaire de la Bande de Gaza.

44. Voir Stanford J. Shaw, The Jews of the Ottoman Empire and the Turkish Republic, New York, New York University Press, 1991, tout particulièrement pp. 210-218 ; pour l'historiographie, voir Jacob M. Landau, «The 'Young Turks' and Zionism : Some Comments » in Jabob Landau, Jews, Arabs, Turks. Selected Essays, Jerusalem, The Magnes Press, The Hebrew University, 1993, pp. 169-177.

45. HMS 21B ; voir aussi HMS 02 et Charte, art.28.

46. Anonyme, Sd., Al-Islâm wa-l-Qadiyya Al-Filastîniyya (L'islam et la cause palestinienne). Le texte a été rédigé par Ahmad Sâdiq (qui signe une adaptation française de ce texte dans Al-Muntaka, hiver 1985, pp. 1-16, sous le titre « La Palestine à l'heure de l'islam ", pseudonyme de Bachîr Nâfic, l'un des idéologues du Jihad islamique lors de sa formation à la fin des années soixante-dix et au début des années quatrevingt.

47. Selon l'expression de François Burgat, Face à l'islamisme, Paris, La Découverte, 1995.

48. Al-Nahâr, Jerusalem, 10 Janvier 1994.

49. Reproduit in Al-Sabîl, 26. 04. 94.

50. Selon les catégories d'Olivier Roy, L'échec de l'islam politique, Paris, Le Seuil, 1992. Gilles Kepel, La revanche de Dieu, Paris, Le Seuil, 1990, parle d'islamisation « par le haut » (révolutionnaire) et « par le bas » (néo-fondamentalisme).

INDEX

Index géographique : Palestine

Mots-clés : territoire(s) et territorialité, Exilés 